\title{
A Critical Review of Advanced Experimental Techniques to Measure Two- Phase Gas/Liquid Flow
}

\author{
M.A. Rahman, T. Heidrick and B.A. Fleck ${ }^{*}$ \\ Department of Mechanical Engineering, University of Alberta, Edmonton, Alberta, Canada
}

\begin{abstract}
Gas assisted atomization is becoming increasingly important in many industrial applications such as physical, chemical and petroleum processes. In order to achieve proper atomization it is crucial to have proper mixing of gas (air) and liquid (water) in the feeding conduit before it enters into the nozzle. The flow regime, as well as the flow pattern and structure of the flow, are some of the important parameters that describe two-phase gas/liquid flows, and identify twophase gas/liquid flow regimes. It is also desirable to know under what conditions there is a transition among the different flow regimes (dispersed, stratified, annular, annular-dispersed, slug, wavy-slug, mist-annular). Due to the existence of relative movement in the interfaces and variable interactions between two phases, two-phase gas/liquid flow is a complex transport phenomenon compared to single-phase flow. Still, there is no effective technique to identify the two-phase gas/liquid flow regimes and it is even difficult to capture the accurate flow structures in smaller conduits in turbulent flow cases. Lack of solid and comprehensive theories for predicting and calculating the pressure and void fraction variations in two-phase air/water flow situations has left engineers without essential information for proper design of two-phase flow systems. This review is an effort to explore the state of the present advanced measurement techniques in this field of research. Subsequently, some of the advanced void fraction, photonics and pressure measurement techniques and correlations for identification of two-phase gas/liquid flow regimes and bubble sizes are investigated.
\end{abstract}

Keywords: Two-phase gas/liquid flow, advanced experimental techniques, pressure drop, void fraction, bubble size, flow map.

\section{INTRODUCTION}

Two-phase gas/liquid flows are quite complicated transport phenomena. There are still fundamental aspects of the two-phase gas/liquid flow whose physical descriptions are still unknown and modeling results are questionable. Experimental observations are difficult in this case, as the migration of dispersed bubbles towards the top of the pipe, due to buoyancy, and complicated turbulence interaction causes a highly non-symmetric volume distribution in the pipe cross-section. Often, existing theoretical solutions do not agree with the experimental results. Accurate measurement techniques of two-phase gas/liquid flow are a ubiquitous challenge. Often, existing measurement techniques cannot explain important physical properties and parameters needed to model the two-phase flow phenomena. There is the utmost need to explore novel experimental techniques in order to obtain a better insight into fundamental phenomena associated with two-phase gas/liquid fluid dynamics.

A phase refers to the solid or liquid, or vapour state of matter. A two-phase flow is the flow of a mixture of two phases such as gas (bubbles) in a liquid, or liquid (droplets) in gas. In this paper, special emphasis is given to the horizontal two-phase gas/liquid flow condition. Horizontal two-phase gas/liquid flow can be classified into two major categories a) dispersed flow or b) separated flow. Dispersed phase flows are flows in which one phase consists of discrete

*Address correspondence to this author at the Department of Mechanical Engineering, University of Alberta, Edmonton, Alberta, Canada;

E-mail: brian.fleck@ualberta.ca elements, such as droplets in a gas or bubbles in a liquid and the discrete elements are not connected. In a separated flow, a line of contact separates the two phases. An annular flow is a separated flow in which there is a liquid layer on the pipe wall and a gaseous core [1]. Thus, the accumulated air, in a conduit, can evolve into different flow patterns, from stratified, annular to dispersed flow patterns.

Lack of solid and comprehensive theories for predicting and calculating the pressure and void fraction variations in two-phase air/water flow situations has left engineers without essential information for proper design of two-phase gas/liquid systems [2]. In addition, there is a lack of reliable experimental techniques to obtain the physical properties of the two-phase, two-component flows. In this paper, basic theories and advanced experimental techniques of two-phase gas/liquid flows are reviewed extensively. In the first two sections of this article, basic theories and several useful nondimensional numbers for the two-phase gas/liquid flow are explained. Subsequently, the advanced pressure measurements, void fraction measurements, and photonics and image analysis techniques used in the two-phase gas/liquid flows are reviewed. Finally, several useful correlations to characterize the bubble size in two-phase, air-water horizontal flows are reviewed. This review is a benchmark of the state-of-the-art experimental tools and analysis techniques of the two-phase gas/liquid flows.

\section{BASIC CONCEPTS AND DEFINITIONS}

The basic theory of two-phase, two-component flow is described in this section. The superficial velocity, which is the velocity that either of the phases would flow alone 
occupying the entire cross-section of the pipe $\left(u_{d s}=4 Q_{d} / \pi D^{2}\right.$ or $u_{c s}=4 Q_{d} \pi D^{2}$ ), is an important parameter in the gas-liquid flow system [3]. The void fraction, which is the portion of the pipe cross sectional area occupied by the gas phase, is another important parameter in the gas-liquid flow system. When the velocity of the phases is the same (no-slip), the void fraction is termed the homogeneous void fraction $\left(\alpha_{H}=A_{g} / A_{\text {pipe }}=u_{d s} /\right.$ $\left.u_{d s}+u_{c s}\right)$. This definition of the void fraction is valid for the dispersed bubbly flow [4-6]. However, due to slip between the phases, the homogeneous void fraction is a bit lower (approximately $1 / 1.2$ times lower) than the non-slip condition [7]. Air (Gas) to liquid ratio or $A L R$ (GLR) ratio can be defined as the ratio of the mass flow rate of the gas phase to the mass flow rate of the liquid phase $\left(A L R=m_{d} / m_{c}\right)$. The relationship between the homogeneous void fraction and $A L R$ is straightforward and can be obtained as follows:

$$
\alpha_{H}=\frac{Q_{d}}{Q_{d}+Q_{c}}=\frac{1}{1+\frac{Q_{c}}{Q_{d}}}=\frac{1}{1+\frac{m_{c} \rho_{d}}{m_{d} \rho_{c}}}=\frac{1}{1+\frac{P}{(A L R) \rho_{c} R T}}
$$

where $R$ represents the Universal Gas Constant = $8.3144 \times 10^{-3} \mathrm{~kJ} / \mathrm{mol} . \mathrm{K}, \rho_{C}$ is the density of liquid (water) $=1000\left(\mathrm{~kg} / \mathrm{m}^{3}\right)$, and $T$ resents absolute temperature, $T=293$ $\mathrm{K}$. The response time of a bubble or droplet to change in flow velocity or temperature is important in establishing non-dimensional parameters to characterize the two-phase gas/liquid flow [1]. The momentum response time and the flow field response time comprise the Stokes number $(S t=$ $\left.\tau_{m} / \tau_{f}\right)$. The Stokes number can be further related to the velocity ratio as follows:

$\varphi=\frac{u_{d}}{u_{c}} \approx \frac{1}{1+S t}$

If the Stokes number tends to be zero, there would be noslip between the two phases. In two-phase flow, commonly employed averaging techniques are time, volume and mass averaging [3]. Various forms of averaging have been used in the literature: a) time averaging $[8,9]$, b) volume averaging [10-12], c) flow-area averaging $[8,13,14]$, and d) ensemble averaging [3]. A detailed literature review on averaging techniques of two-phase flows can also be found in literature [15-18]. Two-phase flow modeling is a ubiquitous challenge due to complex interaction between the phases. However, several simplified two-phase flow models can be found in the literature. Two basic assumptions required to consider a flow homogeneous are [3]: a) The time scale for the transport between phases is much shorter than the overall characteristic or system time scale, and b) two phases are in thermodynamic equilibrium, i.e. $V_{p}=V_{C}, P_{p}=P_{c}$, and $T_{p}=T_{c}$. Under this situation one can consider the mixture as a single-phase flow. The mixture, or effective, density can be written as [1]:

$\rho_{m}=\alpha \rho_{d}+(1-\alpha) \rho_{c}$

where, $\alpha$ is the void fraction $\left(V_{d} / V\right)$. Several suggestions have been proposed for the mixture viscosity as follows: a)
For suspension of fluid spheres at low concentration ( $\alpha \leq 0.05$ ) $[11,19,20]$, b) For suspension of solid spheres at low concentration $(\alpha \leq 0.05)$ [21], c) For suspension of low-viscosity gas bubbles at low concentration $(\alpha \leq 0.05)$ [3]. In the case of gas-liquid flows with large void fractions ( $\alpha \geq 0.05$ ) several suggestions have also been provided [2224]. Due to their simplicity, the mixture models are quite advantageous for use in the computational analysis. The drift flux model is based on the concept of analyzing the mixture as a whole rather than in separated phases. However, this model accounts for the relative motion between the phases [3]. The 1-D drift flux model is described in detail for vertical pipe flow [25], vertical rectangular ducts [26] and vertical annular two-phase flow condition [27]. Separated flow models indicate the physical separation of two immiscible fluids flowing in layers. Either EulerianLagrangian (particle trajectory models) or Eulerian-Eulerian models are employed to solve separated flow problems [2832].

\section{DIMENSIONLESS NUMBERS}

In two-phase flow, the use of traditional dimensionless numbers is very limited in correlating data sets [3]. However, there are several important dimensionless numbers found in literature. In liquid-particle motion and particle dynamics, the Stokes number is a very important parameter where particles are suspended in a fluid flow. The Stokes number is defined as the ratio of the particle momentum response time over a flow system time. Mathematically:

$S t=\frac{\tau_{p}}{\tau_{c}}=\frac{\rho_{p} d_{p}^{2} / 18 \mu_{c}}{L / u_{c}}$

Three types of situations can be observed for particles (bubbles/droplets) suspended in fluid, namely: Case a) If $S t<<1$, the response time of the particles is much less than the characteristic time associated with the flow field. In this case the particles will have ample time to respond to changes in flow velocity. Case b) $S t \rightarrow 0$, where the two phases are in thermodynamic or velocity equilibrium. Case c) if $\mathrm{St}>>1$, then the particle will have essentially no time to respond to the fluid velocity changes and the particle velocity will be little affected by fluid velocity change [1]. The Reynolds number quantifies the relative importance of the inertial forces to viscous forces for given flow conditions. In many industrial applications with small droplets/bubbles in twophase, two component flow, the relative Reynolds number is an important parameter as this number determines whether the flow falls into the category of the Stokes flow or not. This number is also a benchmark to determine the appropriate drag coefficient $\left(\mathrm{C}_{\mathrm{D}}\right)$. Particle or relative Reynolds number can be defined as follows:

$\operatorname{Re}_{p}=\frac{\rho_{c} d_{p}\left|u_{c}-u_{p}\right|}{\mu_{c}}$

If $\operatorname{Re}_{p}<1$, the two-phase flow would be termed Stokes flow. In the Stokes flow regime viscous bubbles or drops remain spherical, regardless of the value of the Eötvös number. Even at low relative Reynolds numbers, a wake is 
formed behind the sphere. This is a steady-state wake that becomes stronger as the Reynolds number increases and the inertia of the flow around the bubbles/droplets overcomes the viscosity effects on the surface of the bubbles/droplets [1]. The Froude Number is the ratio of inertial forces to gravitational forces. The Froude number is given by [33]:

$N_{F r}=\frac{u_{m}^{2}}{g D}$

Total, or mixture, velocity can be defined as:

$u_{m}=\frac{Q_{c}+Q_{d}}{A_{d}}=u_{c s}+u_{d s}$

If there were no slip between phases, both the liquid and gas would flow at the mixture velocity. The liquid typically flows at a velocity less than the mixture velocity because of the slip between the phases. When $F r<1$, small surface waves can move upstream; when $F r>1$, they will be carried downstream; and when $F r=1$ (said to be the critical Froude number), the velocity of flow is equal to the velocity of surface waves. The Weber number is a measure of the relative importance of the fluid's inertia compared to its surface tension. This quantity is useful in analyzing the formation of droplets and bubbles. If the surface tension of the fluid decreases, bubbles/droplets will have the tendency to decrease due to higher momentum transfer between the phases. The Weber number can be defined as:

We $=\frac{\text { Inertia }}{\text { Surface }}=\frac{\rho_{c} u_{c}^{2} L}{\sigma}=\operatorname{Re}^{2}\left(\frac{M o}{\text { Eo }}\right)^{-\frac{1}{2}}$

where, $R e$ is the Reynolds number, $E o$ is the Eotvos number, and $M o$ is the Morton Number. In addition to the above dimensionless numbers, the Knudsen Number and Galileo number are also two important numbers in two-phase gas/liquid flow in determining the continuum approximation and the motion of a bubble/droplet under the action of gravity in the gravity-driven viscous flow, respectively.

\section{ADVANCED PRESSURE MEASUREMENT TECHNIQUES}

In two-phase gas-liquid flow, accurate pressure prediction assists to evaluate design criteria to prevent rupture [34] and pulsation. Since a slug flow is a periodic phenomenon, if the frequency of the wave is near to the frequency of the structure, then it can lead to resonance and can increase damage risk to the conduit [2]. In two-phase gas-liquid flow, average density, flow velocity, and flow regime prediction, in combination with transient void fractions can be extracted from the pressure pulse data $[2,35]$. Pressure fluctuations can also be used to discover and locate leaks in long water tunnels and offshore pipelines [36]. In addition, studies show that the velocity and attenuation of the pressure waves are a function of the frequency and bubble radius [37]. Accurate prediction of the pressure drop in horizontal conduits is of great interest in many industries, especially in the oil industry.

A study [38] provided two-phase friction factor correlations based on 2435 pieces of data from gas-liquid flow experiments in horizontal pipelines. They proposed several analytical expressions for the friction factor covering both laminar and turbulent two-phase, gas-liquid flows, which were obtained by fitting the transition region between laminar and turbulent flows. However, in the aforementioned study the Reynolds number was based on the mixture velocity and the liquid kinematic viscosity. It will be more appropriate to calculate the Reynolds number and the Fanning friction factor for gas-liquid flow based on mixture kinematic viscosity rather liquid kinematic viscosity. In twophase gas/liquid flows the mixture kinematic viscosity is lower than the single-phase kinematic viscosity.

Dimensionless pressure gradients are usually expressed as friction factors. For a single-phase flow the Moody chart provides this friction factor reliably. The pipe roughness is an important factor in the Moody diagram. In a two-phase flow, the friction factor increases with 0.25 power of Reynolds number for turbulent flows [38]. In this study, novel Moody diagrams for gas-liquid flows in horizontal pipelines in terms of a mixture Fanning friction factor and mixture Reynolds number are proposed. The aforementioned study pointed out that pipe roughness does not have a major effect on turbulent gas-liquid, two-phase flow. However, the effects of interacting phases appear to dominate the effects of wall roughness. Previous studies [22,39] used various combinations of dimensionless parameters to find out the relative error between the correlated and experimental values. The dimensionless parameters introduced by a study [38] are presented below. The Fanning friction factor for the gas-liquid mixture, $f_{m}$, is defined as:

$f_{m}=\frac{(\Delta P / L) D}{2 \rho_{m} u_{m}^{2}}$

where the pressure drop per unit length $(\Delta p / L)$ in $\left(\mathrm{N} / \mathrm{m}^{3}\right)$ is related to the wall shear stress $\left(\tau_{w}=D \Delta P / 4 L\right)$ in $\left(\mathrm{N} / \mathrm{m}^{3}\right)$, $D$ is the pipe diameter (m), $u_{m}=u_{s g}+u_{s l}$ is the mixture velocity $(\mathrm{m} / \mathrm{s})$, which is defined in terms of the superficial gas velocity $\left(u_{s g}=4 Q_{g} / \pi D^{2}\right)$ and the superficial liquid velocity $\left(u_{s l}=4 Q_{l} / \pi D^{2}\right) . Q_{g}$ and $Q_{l}$ are the gas and liquid volumetric flow rates, respectively. The mixture Fanning friction factor, $f_{m}$, was correlated with a mixture Reynolds number $\left(R e=u_{m} D / v_{l}\right)$. In the aforementioned study it was thought that the frictional resistance of the mixture was due mainly to the liquid phase. A single composite equation that can be used to predict the mixture friction factors for a wide range of gas/liquid flow rates, viscosity values, and different flow patterns was obtained in another study $[40,41]$. The equation was given by:

$$
f_{m}=0.0925 \operatorname{Re}^{-0.2534}+\frac{13.98 \operatorname{Re}^{-0.9501}-0.0925 \mathrm{Re}^{-0.2534}}{\left(1+\left(\frac{\mathrm{Re}}{293}\right)^{4.864}\right)^{0.1972}}
$$

The spread of the experimental data around the composite friction factor correlation is shown in Fig. (1) [42]. In this study, it was pointed out that the correlation had 
an average error of $-4.27 \%$ and an average absolute error of $20.27 \%$. The best agreements were obtained for slug and dispersed bubble flow data, with an average absolute error of $12.41 \%$ and $8.98 \%$, respectively. The worst agreements were obtained for annular and stratified flow data, with an average absolute error of $38.65 \%$ and $34.57 \%$, respectively. Another study [43] proposed the void fraction correlations in the form:

$$
\alpha=e \operatorname{Re}^{r}(1-\lambda)^{l \operatorname{Re}^{S}}
$$

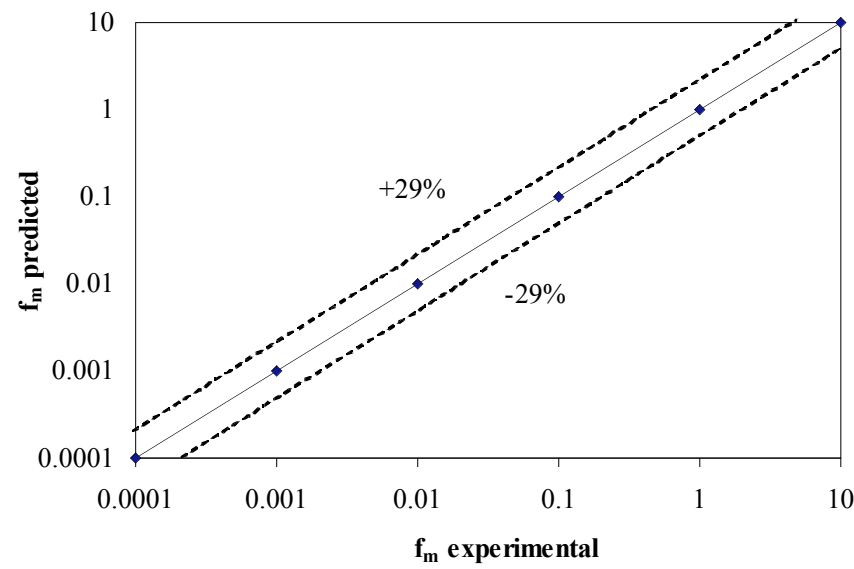

Fig. (1). Predicted mixture Fanning friction factor $v s$ experimental mixture Fanning friction factor for the universal composite correlation, adapted from [38]. Experiments were conducted for annular, dispersed bubble, slug, stratified smooth and stratified wavy flow.

where $\lambda$ is the flow rate fraction $\left.\left(\lambda=Q_{g} / Q_{g}+Q_{1}\right)\right)$. The friction factor correlations are in the form [43]:

$f_{m}=\alpha^{p}(1-\lambda)^{n} 16 / \operatorname{Re}^{m}$

Values of the parameters $e, r, l, s, p, n$, and $m$ are $0.59,0.1,0.16,0.17,-0.10,1.12$, and 0.96 , respectively. The presence of the void fraction in the correlations shows that the friction factor is a function of the void fraction. It was pointed out that two flows with the same Reynolds number, $\operatorname{Re}$, and $(1-\lambda)$ would give rise to different friction factors if the void fractions are different. Pressure drop correlations were provided for annular horizontal two-phase air-water flow as follows:

$f=\frac{\Delta p}{(L / D)\left(\rho_{g} u_{s g}^{2}\right) / 2}$

In the same study, it was also pointed out that the pressure drop data for all geometries were well-correlated by the Lockhart-Martinelli parameter, $X_{t t}$, using the relation:

$$
f=0.215 X_{t t}+0.01
$$

The Lockhart-Martinelli parameter for turbulentturbulent flow was calculated using a correlation [44]:

$$
X_{t t}=\left(\frac{1-x}{x}\right)^{0.9}\left(\frac{\rho_{g}}{\rho_{l}}\right)^{0.5}\left(\frac{\mu_{l}}{\mu_{g}}\right)^{0.1}
$$

The mass quality, $x$, is defined by: $x=m_{g} /\left(m_{g}+m_{l}\right)$. Where, $m_{g}$ is the mass flow rate of the gas phase $(\mathrm{kg} / \mathrm{s})$ and $m_{l}$ is the mass flow rate of the liquid phase $(\mathrm{kg} / \mathrm{s})$.

\section{Top Piezometer}

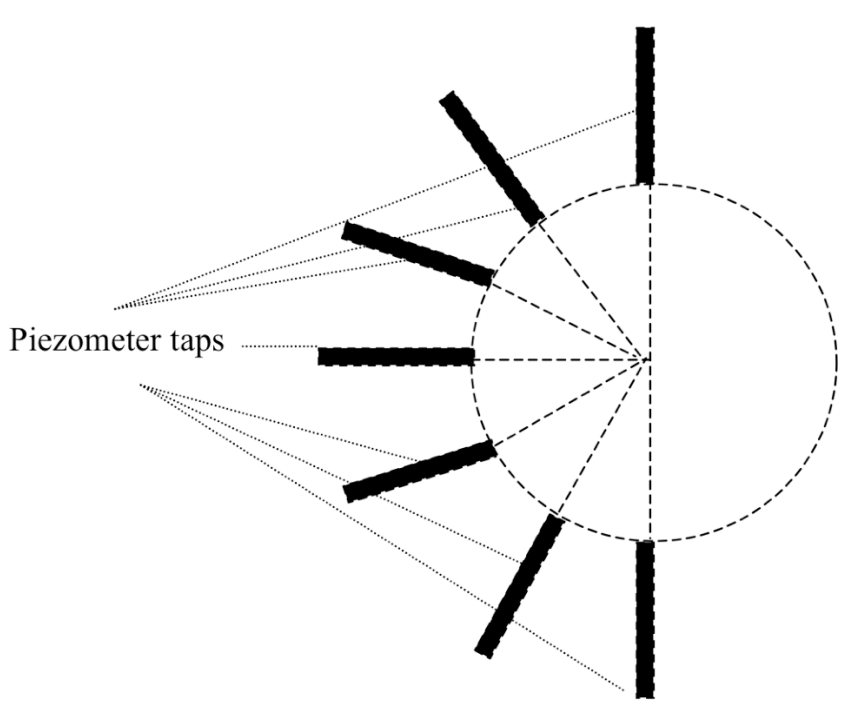

Bottom Piezometer

Fig. (2). The arrangement of pressure sensors at a pipe section. Adapted from [2].

Another study [2] showed that more intensive phase interaction initiates stronger fluctuations. It was suggested that the maximum pressure inside the pipe would reach up to 10 times the upstream hydrostatic pressure. The experimental set-up was used in the experiment [2] is depicted in Fig. (2). Another study [45] showed that when the Reynolds number was greater than $10^{4}$, the effects of viscosity could be neglected; then the dimensionless pressure head can be written as:

$\frac{P}{h}=f\left(C, K_{f}, \alpha, F r, S t, W\right)$

where, $P$ is the pressure inside the pipe $(\mathrm{Pa}), h$ is the headwater $\left(k u_{l}^{2} / 2 g\right.$ in $\left.\mathrm{m}\right), C$ is the air acceleration number $\left(C=Q_{g} / Q_{g}+Q_{l}\right), K_{f}$ is the friction coefficient ( $K_{f}=f_{T P} \frac{L}{D}$, here, $L$ is the characteristic slug wavelength, $D$ is the pipe diameter, $\alpha$ is the void fraction $\left(\alpha_{H}=u_{d s} / u_{d s}+u_{c s}\right), \quad F r \quad$ is the Froude number $\left(N_{F r}=u_{m}^{2} / g D\right.$ or $C / \sqrt{L g}$ or $\left.Q_{l}+Q_{g} / \sqrt{g D^{5}}\right), S t$ is the Strouhal number ( $S t=2 D f / u_{m}, f$ is the wave frequency), and $W e$ is the Weber number $\left(W e=\rho_{c} u_{c}^{2} L / \sigma\right)$. The parameter $f_{T P}$ is the two-phase gas-liquid flow friction factor and can be expressed as [46]:

$f_{T P}=0.08\left(\frac{G D}{x_{m} \mu_{g}+\left(1-x_{m}\right) \mu_{l}}\right)^{-0.25}$ 
where $G$ is the mixture velocity $(\mathrm{m} / \mathrm{s})$. In this study the best equation for predicting mean pressure in air-water two-phase flow was introduced as below:

$$
\frac{P}{h}=\frac{0.26 F r^{1.43} K_{f}^{0.81} \alpha^{0.03}}{S h^{0.19} C^{0.2} W^{0.26}}+1.2
$$

Another study [43] used pressure transducers, temperatures transducers, and fast closing valves as their experimental methods. The flow characteristics were: horizontal two-phase flow, mineral oil and air as working fluid, $2.54 \mathrm{~cm}$ diameter, and $12 \mathrm{~m}$ and $12.8 \mathrm{~m}$ long tygon tubes. Another study [47] used U-tube water manometers to measure pressure drops. In addition, an optical measurement was used to measure local liquid film thickness $[48,49]$. The flow characteristics were: annular, horizontal two-phase flow, air and water as working fluid, round $(12.7 \mathrm{~mm}$ and $25.4 \mathrm{~mm} \mathrm{ID})$, square $(15.2 \times 22.7 \mathrm{~mm})$ tube was used, both $6.5 \mathrm{~m}$ long. Another study [50] measured pressure drop using Validyne differential pressure transducers operating in the range of $225-500 \mathrm{~mm} \mathrm{H}_{2} \mathrm{O}$. The pressure taps were 0.825 $\mathrm{m}$ apart. The pressure drop signal was recorded at a frequency of $250 \mathrm{~Hz}$ for a period of $5 \mathrm{~min}$. The flow characteristics were: two-phase, gas-liquid flow in horizontal conduits, air and water as working fluids, square crosssection channel ( $H=0.02425 \mathrm{~m}$, a length of $2.3 \mathrm{~m}$.). Liquid flow rates of $2.77 \times 10^{-2} \mathrm{~kg} / \mathrm{s}$ to $2.88 \times 10^{-2} \mathrm{~kg} / \mathrm{s}$ and gas flow rates of $7.73 \times 10^{-3} \mathrm{~kg} / \mathrm{s}$ to $1.49 \times 10^{-2} \mathrm{~kg} / \mathrm{s}$ were used.

In addition to the above experimental techniques, there are several studies found in literature that attempt to obtain a two-phase experimental pressure drop. Oscillatory characteristics and pressure drop in vertical two-phase churn flows were experimentally investigated [51]. In the aforementioned study, the vertical test tube was made from acrylic resin and the inner diameter was $25.8 \mathrm{~mm}$. Wavy stratified two-phase, gas-liquid flow in the horizontal Plexiglas pipes of $0.024 \mathrm{~m}$ and $0.0508 \mathrm{mID}$, superficial velocity of $510-25 \mathrm{~m} / \mathrm{s}$ for air and $50.01-0.05 \mathrm{~m} / \mathrm{s}$ for the liquid (electro-chemical solution) was investigated [52]. It was pointed out that liquid-to-wall shear stress tended to decrease circumferentially of a $0.0005 \mathrm{~m}$ in ID pipe. An analytical solution of gas wall, liquid wall and interfacial friction factors for two-phase horizontal co-current pipe flow was proposed and verified with reliable experimental data [53]. Two equations were proposed in attempt to predict liquid wall friction factors:

$$
\begin{aligned}
& f_{l}=0.263\left[(1-\alpha) \operatorname{Re}_{s l}\right]^{-.05} \\
& f_{l}=0.0262\left[(1-\alpha) \operatorname{Re}_{s l}\right]^{-.0 .139}
\end{aligned}
$$

where $\alpha$ is the void fraction and $\operatorname{Re}_{s l}$ is the Reynolds number based on liquid superficial velocity. The first equation can be used in smaller diameter pipes and the second equation can be used in large diameter pipes. However, in this study the dimension of the smaller and larger diameter pipes is not clear.

\section{ADVANCED VOID FRACTION MEASUREMENT TECHNIQUES}

Void fraction or volume fraction, $\alpha$, (as defined earlier) is an important parameter in two-phase gas-liquid flow. It has always been a challenge to measure volume fraction of the phases, due to the highly non-symmetric nature of twophase gas-liquid horizontal flow, e.g. bubbles can coalesce, break-up, or interact with the conduit wall, which makes the flow extremely unstable. In literature different types of techniques were implemented to measure the void fraction in two-phase, gas-liquid closed flow. Some of these are described in this section.

In several literature sources, particular emphasis is given to the Electrical Process Tomography methods, due to their inherent suitability for widespread online use [54]. A review article by Beck et al. [55] broadly explains the tomographic technique and the selection criteria of the sensors, which is listed in the following paragraph. As defined in the literature, the tomographic technology involves the acquisition of measurement signals from sensors located on the periphery of an object, such as a process vessel or pipeline. A tomographic system can measure the ratios of two phases within a resolved image element, even though the individual particles cannot be resolved. Optical, X-ray, $\gamma$-ray, and position emission tomography methods use electromagnetic radiation with approximate spatial resolution of $1 \%$ (percentage of diameter of cross section). X-ray and $\gamma$-ray method are slow and radiation safety assurance is required. The position emission tomography method needs a labeled particle and the process is not on-line. Nuclear magnetic resonance uses electromagnetic resonance with an approximate spatial resolution of $1 \%$. This is a fast and expensive method. Another complex to use method is the ultrasonic measurement, which uses acoustics with an approximate spatial resolution of 3\%. This method has sonic speed limitations. Finally, the capacitive, conductive and inductive method works through the measurement of electrical properties of different phases, with an approximate spatial resolution of $5 \%$. This method is fast, low cost and suitable for either a small or large scale experimental set-up. As an example, with the electrical tomographic measurement technique a temporal resolution of up to 100 frames per second is achieved, whereas with the x-ray tomography spatial resolutions of only $0.4 \mathrm{~mm}$ are possible [56]. Electrical capacitance tomography (ECT) to image multiphase flows for inner diameter exceeding $1 \mathrm{~m}$ was conducted with good performance in regard to resolution, linearity, and stability [57]. An online and rapid direct flowpattern identification method using electrical capacitance tomography was also proposed without the need for imaging [58].

The void fractions in bubbly flows were investigated by several researchers using optical probes. A fiber optics method was implemented [59-61] to measure the void fraction. It was found that the rise time of the signal pulses were created when bubbles crossed the probe tip and were closely correlated with the bubble velocities. Therefore, 
bubble velocities and hence bubble sizes could be estimated using a single probe. It was observed that the correlation between the rise time and the bubble velocity varied significantly between probes, but was only a weak function of water type (i.e., freshwater or seawater) and the bubble impaction angle. This method provided high accuracy and stable measurements. The size and velocity of each bubble were measured with this method. This method was also applicable for non-conductive fluid. However, the use of fiber optic probes to measure very small void fractions was not recommended because of the large errors that were anticipated [59]. The effect of bubble deflection is expected to be more pronounced as the bubble radius and velocity decrease and as the liquid viscosity increases [60]. In the aforementioned study the bubble diameters ranged from approximately 1 to $6 \mathrm{~mm}$ and bubble velocities from 5 to $120 \mathrm{~cm} / \mathrm{s}$, the water velocity was varied from 45 to $92 \mathrm{~cm} / \mathrm{s}$. Another study [62] used an optical signal derived from a diode laser driven by a constant current then launched into a single-mode optical fiber and transmitted, through a fiber coupler, to the signal fiber ( $125 \mu \mathrm{m}$ in diameter) inserted into the test fluid. By analyzing the signal, the velocity and void fraction ratio of each phase could be obtained. However, there is intrusion to the fluid by the tiny fiber probe. Another study [63] developed a fiber-optic probe to measure local void fraction. Each probe has a conical tip and is made from an optical fiber of $170 \mu \mathrm{m}$ diameter. Application of a dual optical probe for local volume fraction, drop velocity and drop size measurements in a kerosene-water, liquid-liquid, two-phase flow was also investigated [64]. In the experiment, measurements were carried out in a large-scale vertical two-phase facility, mainly at the pipe center-line, to demonstrate the advantages of using optical fibers with normal cut ends in a kerosene-water, two-phase flow. High reliability of this measurement technique for detailed studies of the drop component of liquid-liquid, two-phase flow could be possible. Other previously used fiber optic techniques can be found in literature [65-69].

Several researchers conducted void fraction determination by means of multibeam gamma-ray densitometers. Several studies on implementing gamma-ray densitometers showed that multi-beam gamma-ray densitometers with detector responses examined by neural networks can analyze a two-phase flow void fraction with high accuracy [70,71]. Void fraction and flow regime in oil/gas pipes could be measured with an error of $3 \%$ for all of the flow regimes. Oil-water two-phase flow experiments were conducted in a $15 \mathrm{~m}$ long, $8.28 \mathrm{~cm}$ diameter, inclinable steel pipe using mineral oil (density of $830 \mathrm{~kg} / \mathrm{m}^{3}$ and viscosity of $7.5 \mathrm{mPa} . \mathrm{s}$ ) and brine (density of $1060 \mathrm{~kg} / \mathrm{m}^{3}$ and viscosity of $0.8 \mathrm{mPa} . \mathrm{s}$ ) [72]. In addition, other research results showed that mixture densities obtained with gammaray densitometers agree well with the direct measurements made by using quick-closing valves [73]. One of the disadvantages of the gamma-ray densitometers is the shielding requirement of the gamma-ray.

Various attempts have been made in the past to measure the void fraction of two-phase bubbly liquid flows using capacitive sensors. Capacitance sensors for instantaneous void fraction in air-oil, two-phase flow were developed [7476]. This method could effectively identify the different flow regimes although it was not effective while there was high water loading. In addition, synchrotron $X$-rays [77], pulsed neutron technique [78], conductance probes [79], ultrasonic technique [80], and ring impedance probes [81] have been used successfully to measure the void fraction in two-phase flow systems.

One of the more recent techniques is the microwave flow sensor [82]. Using radio frequency signals, the non-invasive meter will measure the mass-flow, quality and void fraction of any non-conducting vapor-liquid mixture. This method can identify the quality and void fraction. These sensors are good for cryogens, refrigerants and low flow rate two-phase, gas-liquid flow. Since these instruments are entirely datadriven, the results depend heavily on the amount and quality of the data that is acquired for a given application. The probe, however, cannot measure mixtures with significant water content.

Quick-closing valves provide an exact void fraction measurement and are useful for calibrating or comparing against other methods. Void fraction of two-phase flow is often measured by isolating a section in the conduit; [83-88] called the quick-closing-valves $(Q C V)$ technique. However, most of the studies were conducted in vertical bubble column. A technique for synchronizing valves and determining bubble rise velocities in two-phase flow is presented in a study by [89]. It is very crucial to commence the closing of both valves simultaneously. Error in void fraction measurements by the $Q C V$ due to asynchronization of the vales can be expressed as [89]:

$\% \quad$ Error $=\frac{100 u_{m} t_{a c}(1-\alpha)}{\alpha l_{c}}$

where, $u_{m}$ is the mixture velocity in the conduit, $\alpha$ is the void fraction, $t_{a c}$ is the asynchronization closing time, and $l_{c}$ is the closing length between the two valves. Previous studies showed that for a two-phase bubble flow at low flow rates and a closing length of $5 \mathrm{~m}$, for each millisecond of delay there would be $1 \%$ error.

\section{ADVANCED PHOTONICS AND IMAGE ANALYSIS TECHNIQUES}

The flow regime description obtained by the photonics measurement [90] is described in this section. Description of the different flow patterns is depicted in Fig. (3). The stratified flow regime is characterized by a complete separation of the liquid and gas phases. When both of the liquid and gas flows are laminar and no fluctuations at the flow interface can be detected, the flow pattern is called stratified (stratified smooth). As the gas mass flow rate is increased, instabilities form at the liquid-gas interface due to the interfacial velocity differential (termed as KelvinHelmholtz instability). This flow pattern is called wavy flow (stratified wavy) and is characterized by the formation of small interfacial waves. In larger diameter tubes these waves can amplify, producing a crest. These waves are easier to detect in large diameter tubes and the wave height can be large enough to allow the waves to break up. In small diameter tubes [90] large breaking waves were typically not observed. The intermittent flow regime is characterized by 
discontinuities in the liquid and gas flow. Elongated bubble flow (plug flow) is characterized by a continuous stream of gas plugs flowing in the liquid. A thin film of liquid coats the tube wall and surrounds the gas plug. Small disturbances may exist fore and aft of the bubbles, but as a whole the plugs remain intact and uniform. As the gas mass flow rate is increased, these disturbances amplify until the aft portion of the plug breaks apart into smaller bubbles. At this point, the flow pattern becomes slug flow.

The annular flow regime consists of a nearly complete separation of the liquid and gas along the circumference of the tube wall. The first form of annular flow occurs when the surfaces of waves in wavy flow amplify to the extent that they touch the top of the tube wall. This flow pattern is known as wavy-annular flow (pseudo slug flow). As the mass flow rate is increased, the liquid is pushed up around the circumference of the tube wall by the increase in the gas momentum and falls downward under gravity in the form of annular waves. When the liquid coats the tube wall completely (forming an annular ring of the liquid phase) and the gas flows through the core of the tube, the flow pattern is known as annular flow. Dispersed flow occurs when the liquid flow is turbulent and the gas phase is in laminar or turbulent flow. When the gas flow is laminar, small bubbles are driven by buoyancy forces and flow primarily in the top half of the tube. This pattern is known as bubble flow. As the Reynolds number of the gas increases, keeping other variables constant, the bubble size decreases and the bubbles begin to disperse across the entire tube cross section. This flow pattern is known as dispersed bubble or dispersed flow.

Flow patterns for concurrent air-water mixtures in horizontal round and rectangular tubes were determined by high-speed video analysis to develop flow regime maps and the transitions between these flow regimes [90]. In this study, gas and liquid superficial velocities ranged from 0.10 to $100 \mathrm{~m} / \mathrm{s}$, respectively. The test sections for the round tubes were made of Pyrex glass. Liquid and gas flow rates ranged from 0.013 to $8.331 \mathrm{~m}^{3} / \mathrm{s}$ and 0.002 to $1.18 \mathrm{~m}^{3} / \mathrm{s}$, respectively. The uncertainties in the flow rate measurements were estimated to be $\pm 4 \%$. The recording equipment used was a Canon ES5000 $8 \mathrm{~mm}$ video camera with a zoom range of $40 X$. A shutter speed of $0.0001 \mathrm{~s}$ and a frame speed of $0.003 \mathrm{~s}$ were used. Four different types of round tubes were examined in this study at: $5.5 \mathrm{~mm}, 2.6 \mathrm{~mm}, 1.75 \mathrm{~mm}$ and $1.30 \mathrm{~mm}$. They observed several flow patterns such as bubbly, dispersed, elongated bubble, slug, stratified, wavy, wavy annular and annular flow patterns. Further studies on advanced photonics measurements can be found in literature [47,91-105]

In literature, different flow pattern maps were proposed to predict the two-phase gas/liquid flow regimes. Although in literature these flow maps were investigated for larger length scale experimental set-up, the applicability of these maps to smaller length scale set-up was not conducted extensively. In this context, in the present study the different flow maps would be tested for different flow input conditions in order to determine the best flow map for the present nozzle assembly. A brief theory behind the different flow maps are described in this section.

\subsection{Taitel and Dukler Flow Maps $[90,106]$}

Taitel and Dukler attempted to predict the flow regimes for concurrent gas-liquid flow in pipes using a momentum balance (Fig. 4). The momentum balance was nondimensionalized with respect to $D$ for length, $D^{2}$ for area, $u_{s g}$ for gas velocities, and $u_{l s}$ for liquid velocities. Flow regime transition was defined by a set of non-dimensional parameters, such as $X, F, K$, and $T$.

$$
X=\left[\frac{(d P / d x)_{l}}{(d P / d x)_{g}}\right]^{1 / 2}
$$

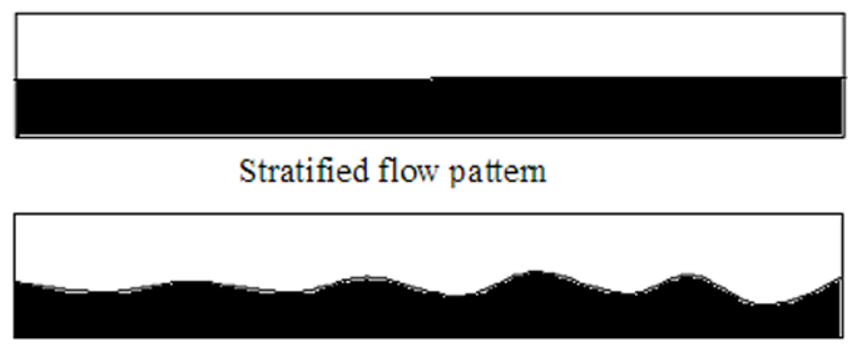

Wavy stratified flow pattern

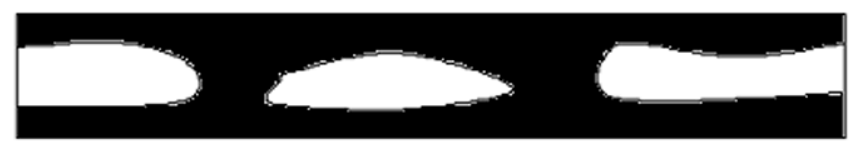

Elongated bubble flow pattem (intermittent regime)

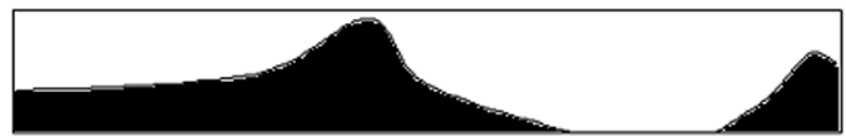

Slug flow pattem (intermittent regime)

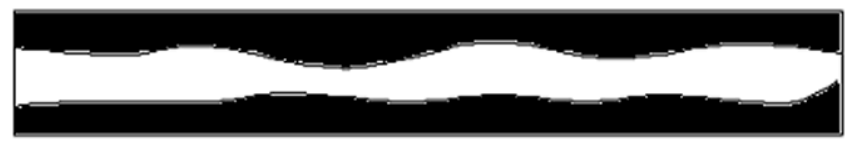

Wavy annular flow pattern

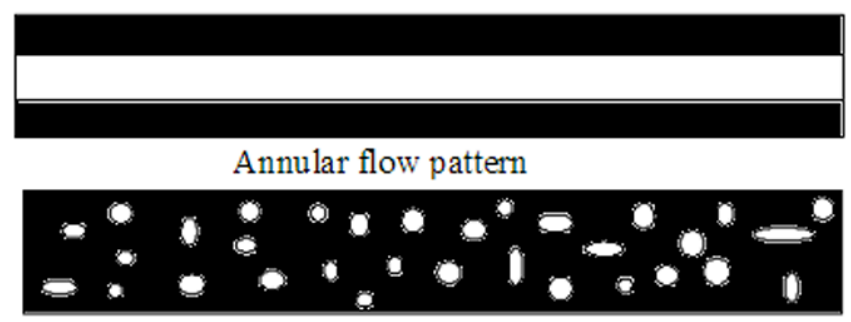

Bubble flow pattern

Fig. (3). Description of flow regimes and patterns. Adapted from [90]. The back part indicates liquid phase and white part indicates gas phase.

$$
\begin{aligned}
& F r=\frac{\rho_{g} u_{g s}}{\sqrt{\rho_{g}\left(\rho_{l}-\rho_{g}\right) D g}} \\
& F=\sqrt{\frac{\rho_{g}}{\left(\rho_{l}-\rho_{g}\right)}} \frac{u_{g s}}{\sqrt{D g \cos \theta}}=\sqrt{\frac{\rho_{g}}{\left(\rho_{l}-\rho_{g}\right)}} F r^{1 / 2}
\end{aligned}
$$

where, $X$ is the Martinelli parameter, $F$ is modified Froude number, $\theta$ is the angle of inclination, $D$ is the diameter of 
the tube, $x$ is the axial direction, and $P$ is the pressure inside the conduit.

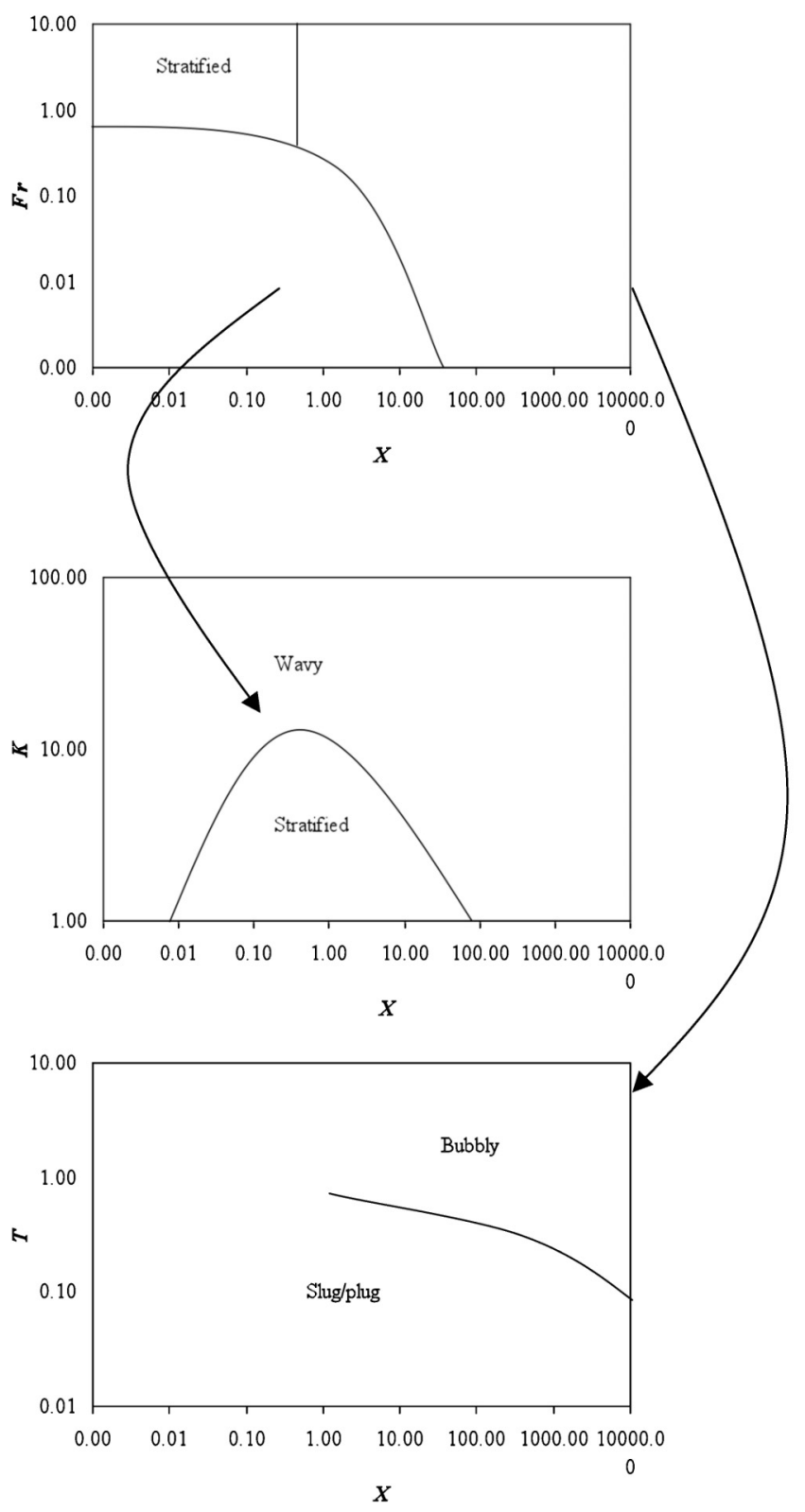

Fig. (4). Taitel and Dukler [106] map for flow pattern determination in a horizontal tube.

$K=\left[\frac{\rho_{g} \rho_{l} u_{s g}^{2} u_{s l}}{\left(\rho_{l}-\rho_{g}\right) g \mu_{l} \cos \theta}\right]^{1 / 2}$

$T=\left[\frac{(d P / d x)_{l}}{\left(\rho_{l}-\rho_{g}\right) g \mu_{l} \cos \theta}\right]^{1 / 2}$

where, $g$ is the gravity, and $\mu$ is the dynamic viscosity.

\subsection{Breber Map [107]}

A Breber map is depicted in Fig. (5). This map is divided into square regions, which is easier to implement. This map makes use of the Martinelli number and the Wallis factor as axes. The Wallis factor is defined as:

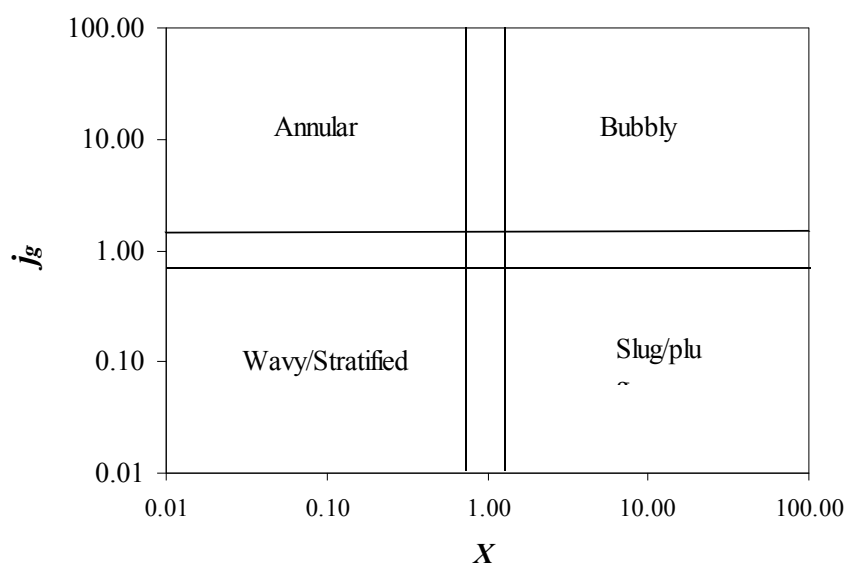

Fig. (5). Breber [108] flow transition map for determining the flow pattern in two-phase flow in a horizontal tube.

$j_{g}^{*}=\frac{\rho_{l} u_{s l} x}{\sqrt{D g \rho_{g}\left(\rho_{l}-\rho_{g}\right)}}$

whereas the Martinelli number is defined as:

$X=\left(\frac{1-x}{x}\right)^{0.9}\left(\frac{\rho_{g}}{\rho_{l}}\right)^{0.5}\left(\frac{\mu_{l}}{\mu_{g}}\right)^{0.1}$

where $x$ is the quality. A study [109] conducted an experiment to investigate the validity of the Breber map and found out that there was a good consistency between the experimental result and the Breber map.

\subsection{Baker Map [107]}

The Barker [110] map for air-water flow is depicted in Fig. (6). The axes are defined in terms of $u_{s g} \rho_{g} / \lambda$ and $u_{s l} \rho_{l} / \lambda$, where, $u_{s g} \rho_{g}=G_{s}=$ mass flux of gas phase $\left(\mathrm{kg} / \mathrm{m}^{2} \mathrm{~s}\right)=($ gas mass flow rate/tube cross-sectional area) and $u_{l s g} \rho_{l}=G_{l}=$ mass flux of liquid phase $\left(\mathrm{kg} / \mathrm{m}^{2} \mathrm{~s}\right)=$ (liquid mass flow rate/tube cross-sectional area).

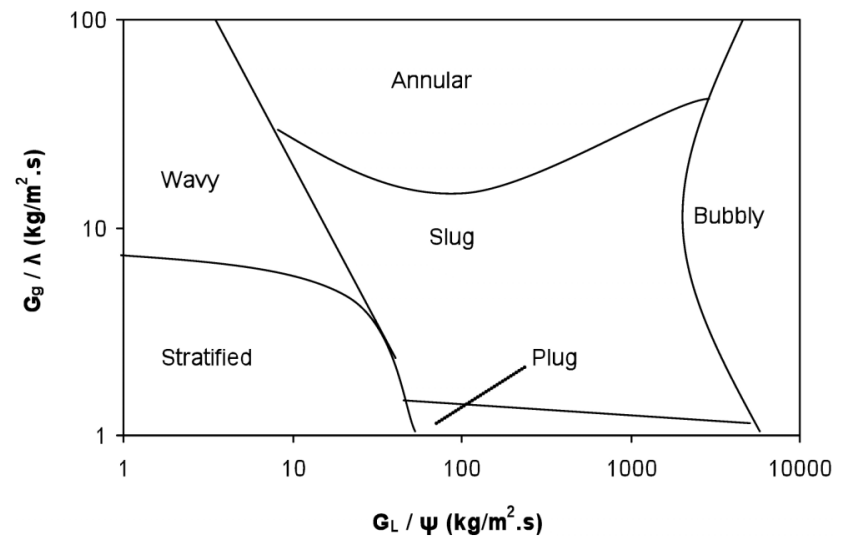

Fig. (6). Baker [110] flow pattern map for horizontal flow in a tube.

The parameter $\lambda$ and $\psi$ are defined as follows: 
$\lambda=\left(\frac{\rho_{g} \rho_{l}}{\rho_{\text {air }} \rho_{\text {water }}}\right)^{1 / 2}$

$\psi=\frac{\sigma_{\text {water }}}{\sigma}\left|\frac{\mu_{l}}{\mu_{\text {water }}}\left[\frac{\rho_{\text {water }}}{\rho_{l}}\right]\right|^{1 / 3}$

where, $\rho_{l}$ is the liquid density $\left(\mathrm{kg} / \mathrm{m}^{3}\right) ; \rho_{g}$ is the gas density $\left(\mathrm{kg} / \mathrm{m}^{3}\right), \rho_{\text {water }}=1000 \mathrm{~kg} / \mathrm{m}^{3}$ is the density of water; $\rho_{\text {air }}=$ $1.23 \mathrm{~kg} / \mathrm{m}^{3}$ is the density of air; $\mu_{l}$ is the liquid viscosity $\left(\mathrm{N} . \mathrm{s} / \mathrm{m}^{2}\right), \mu_{\text {water }}=10 \times 10^{-3} \mathrm{~N} . \mathrm{s} / \mathrm{m}^{2}$ is the viscosity of water; $\sigma$ is the surface tension $(\mathrm{N} / \mathrm{m})$ and $\sigma_{\text {water }}=0.072 \mathrm{~N} / \mathrm{m}$ is the surface tension of air-water. The Baker map works well for water/air and oil/gas mixtures in tubes with smaller diameters, not bigger than $50 \mathrm{~mm}$ [111].

Data obtained from a study [112] was consistent with the Taitel and Dukler map for a $25 \mathrm{~mm}$ diameter tube. For smaller tubes, a large deviation from the Taitel and Dukler map was reported [113]. Visual identification of the flow regimes was plotted on the flow regime map, which has been proposed [108] for condensation application. The results indicated consistency between the observations and the trends predicted by the Breber map..

\section{BUBBLE SIZE IN TWO-PHASE, AIR-WATER HORIZONTAL FLOWS}

Effective bubble size, density and distribution prediction is crucial in two-phase, two-component flows. Due to highly non-uniform volumetric flow distribution and intermittency in the flow it is extremely difficult to predict the accurate bubble size distribution in this type of flow. This uncertainty of the bubble size prediction is exaggerated if the feeding pipe length is short as in our preset study (36.8 cm long); since the two-phase flow is not fully developed within this short pipe length. Thus, a fairly reliable statistical tool is required to find out the uncertainty level in the bubble size estimation. In petro-chemical process industries most of the light crude oil upgrading processes is associated with twophase, two-component flows in the feeding nozzles. Atomization from the nozzle strongly depends on bubble size in the feeding conduit. Thus, it is essential to have a good understanding and reasonable estimate of the effect of turbulent two-phase, two-component gas (steam/air) and liquid (bitumen/water) flow on bubble size distribution. This knowledge would assist in the design and operation of a system that can achieve high yield bitumen recoveries. To the author's knowledge, there are very few studies that have been conducted for the prediction of bubble size in twophase, air-water horizontal flows [114-117]. There are also several studies found in literature on the transport phenomena of two-phase, two-component gas and liquid flows through pipelines [4,118-129].

A backscatter technique was used to examine drop size distributions in a $0.063 \mathrm{~m}$ pipe (both horizontal and vertical alignment) for a two-phase mixture of kerosene and aqueous potassium carbonate solution. In a recent study, images of droplets or particles produced by shadowgraph by backillumination using an infrared diode laser were investigated with a digital image analysis technique [130]. This technique was potentially capable of sizing particles of arbitrary shape and size and with a wide dynamic range. Another study [131] observed biasing effects for a given depth-of-field, with small droplets being less detectable. Measured image diameters were also found to increasingly underestimate the true diameter with increasing defocus distance [131]. Another study [132] implemented a digital-based image analysis system for the experimental determination of size, spatial distribution and two components of velocity for particles suspended in any clear fluid flow.

Another study [133] was conducted with air and water in a large circulating rig with a $0.105 \mathrm{~m}$ diameter test section. In their experiments the majority of the bubbles were ellipsoidal as shown in Fig. (7).

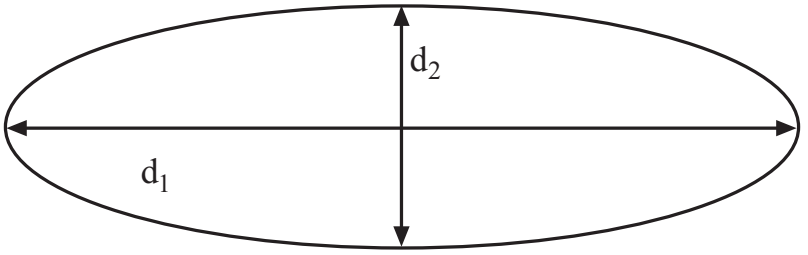

Fig. (7). Major and minor axis lengths of an ellipsoidal bubble.

The bubble diameter, $d_{b}$ can be expressed as [133-135]:

$d_{b}=\sqrt[3]{d_{1}^{2} \times d_{2}}$

where $d_{1}$ and $d_{2}$ are the major and minor axis lengths of the ellipsoid, respectively, as shown in Fig. (9) in a twodimensional projection. Marco et al. [136] conducted experiments by injecting gas (nitrogen) bubbles in a fluorine liquid (FC-72) at ambient temperature and pressure through an orifice (about $0.1 \mathrm{~mm}$ diameter) drilled on a horizontal tube. In this study, the equivalent diameter of the bubble was proposed as [136]:

$d_{e q}=\sqrt[3]{\frac{6 V_{b}}{\pi}}$

where, $V_{b}$ is the bubble volume. Bubbles reflect light both internally and externally. In an image, bright rings within the bubble, named as 'glory', can be seen if internal reflection occurs. By contrast, bright rings surrounding the bubble can be seen if external reflection occurs. This ring obscures the true bubble edge. A study [134] pointed out that neglecting these effects may cause bubble size under-prediction as large as $10 \%$ to $15 \%$.

The bubble size distribution in the horizontal flow of an air-water system (25.4 $\mathrm{mm} I D$ pipeline) was investigated [137] in another study. In the aforementioned study, it was found that the bubbles were broken with a log-normal size distribution along its pathway. However, further downstream of the conduit, due to smaller flow velocity $(1-3 \mathrm{~m} / \mathrm{s})$ and longer longitudinal length of the pipe, coalescence rather than breakage played an important role. It was also pointed out that for all the distributions, the value of the ratio of $D_{99.8} / D_{32}$ is about 2.2 and was fairly independent of average water velocity, pipe length, air volume fraction and air injector diameter. Generally in turbulent two-phase, two- 
component dispersed flow, bubbles break up and coalescence takes place continuously and these processes determine the bubble size distribution. Bubbles having diameters smaller than $d_{\min }$ will have a high tendency to coalesce whereas those having diameters larger than $d_{\max }$ will have a high tendency to break up [137]. A theory used to predict the maximum and minimum bubble size in two-phase air-water flow [137-139] is described in the following section.

\subsection{Maximum Bubble Diameter}

In literature several analytical formulations have been proposed to estimate the maximum bubble size in two-phase, two-component flow. The maximum bubble size [140] is expressed as follows:

$d_{\max }=4 \sqrt{\frac{\sigma}{g \Delta \rho}}$

where $\sigma, g$, and $\Delta \rho$, are the surface tension, the gravitational acceleration, and the density difference, respectively. In turbulent two-phase air-water flows, deformation under the action of the fluctuating eddies occurs if the diameter of a bubble is larger than the Kolmogoroff length scale, $\lambda=\left(v_{c}^{3} / \varepsilon\right)^{1 / 4}$, and is of the order of the length of the energy-containing eddies in the continuous fluid. Here, $\varepsilon$ is the turbulent kinetic energy dissipation rate per unit mass and $v_{c}$ is the kinematic viscosity of the continuous phase. A study [141] hypothesized that a deformed bubble breaks up when the internal pressure force overcomes the surface force. In terms of a critical Weber number it can be written as follows:

$W e_{c}=\frac{\tau}{\sigma / d_{\max }}\left(\frac{\rho_{d}}{\rho_{c}}\right)^{1 / 3}$

where, $d_{\max }$ is the diameter of the largest bubble that can resist the break up in a turbulent flow field, $\sigma$ is the interfacial tension, $\rho_{c}$ and $\rho_{d}$ are the continuous and dispersed phase densities, respectively, and $\tau$ is the stress on the bubble surface due to the turbulent fluctuating eddies in the continuous phase. Several other studies [116,123-125] determined $W e_{c}=1.1$ and others [4] confirmed that for airwater low void fraction system, $W e_{c}=1.05$ and for the oilwater emulsion, it was proposed that $W e_{c}=1.18$ [125]. The maximum diameter of the bubble in the pipe can be written as [116]:

$d_{\max }=1.38\left(W e_{c}\right)^{0.6}\left[\frac{\sigma^{0.6}}{\rho_{c}^{0.5} \mu_{c}^{0.1}}\right]\left(\frac{\rho_{c}}{\rho_{d}}\right)^{0.2}\left(\frac{D^{0.5}}{U^{1.1}}\right)$

Two useful correlations were proposed [125] to predict the bubble length parallel and perpendicular of the flow are as follows:

$l_{H}=0.000406\left(\frac{\rho_{g}^{0.2543} \sigma^{0.8244} D^{0.1141}}{\mu_{g}^{0.5085} \alpha^{0.5215}(\Delta P / L)^{0.5701}}\right)$
$l_{V}=127\left(\frac{\mu_{g}^{0.5085} \alpha^{0.5215} D^{0.3859}}{\rho_{g}^{0.2543} \sigma^{0.0744}(\Delta P / L)^{0.1799}}\right)$

where, $D$ is the diameter of the pipe, $\alpha$ is the void fraction, and $\Delta P / L$ is the pressure gradient in the two-phase, twocomponent flows and is expressed as follows [125]:

$\Delta L / L=\frac{2 \rho_{l} u_{l s}^{2} f}{D}+\frac{3 \rho_{l} u^{2} \alpha C_{D}}{4 l_{H}}$

where, $C_{D}$ is the drag coefficient, $u_{l s}$ is the superficial gas velocity, and $u$ is the average relative velocity between the bubble and liquid phase and is expressed as follows [125]:

$u=\frac{m_{g}}{\rho_{g} \alpha A_{g}}-\frac{m_{l}}{\rho_{l}(1-\alpha) A_{l}}$

The average number bubble per unit volume of pipeline is expressed as:

$N_{B}=\frac{6 \alpha}{\Pi l_{v}^{2} l_{H}}$

A correlation was proposed [137] to predict the maximum bubble size, which can be expressed as follows:

$\frac{d_{\max }}{D}=1.38\left(W e_{c}\right)^{0.6}\left(\frac{\rho_{c}}{\rho_{d}}\right)^{0.2}\left(\frac{\mu_{c}}{\rho_{c} u_{l s} D}\right)^{0.5}\left(\frac{\sigma}{\mu_{c} u_{l s}}\right)^{0.6}$

where, $u_{s l}$ is the superficial water velocity and $D$ is the pipe diameter. Another study [4] pointed out that the critical Weber number or the maximum bubble size increases with the local void fraction. The maximum bubble size observed in the dispersed bubbly flow condition can be correlated as [4]:

$\frac{d_{\max } \tau_{c}}{\sigma}\left(\frac{\rho_{g}}{\rho_{l}}\right)^{1 / 3}=W e_{c r i t}=W e_{c r i t}^{0}\left(1+a \alpha^{-n}\right)$

where, $a$ and $n$ can be evaluated by a best fit procedure. $W e_{c r i t}^{0}$ is the critical Weber number at zero void fraction. The aforementioned study [4] also proposed two correlations from their experimental observation. The first one is:

$W e_{\text {crit }}=1.05\left(1+51.7 \alpha^{-1.5}\right)$

The above correlation is applicable if the maximum stable bubble diameter depends on the dynamic effect of turbulent velocity fluctuations [4]. The second one is as follows:

$W e_{\text {crit }}=0.11\left(1+8.30 \alpha^{-0.80}\right)$

The above correlation is applicable if the maximum stable bubble diameter depends on the mean shear stress. In horizontal two-phase flow, the largest bubble is found very close to the upper wall, at a position where the time averaged radial velocity profile is far from uniform [4]. According to two studies [142,143], a critical Weber number, $W e_{c}$, can be 
used to determine the maximum stable bubble size in a fluid flow field as:

$W e_{c}=\frac{2 \rho_{l} u^{2}\left(r_{b}\right)_{\max }}{\sigma}$

where, $\left(r_{b}\right)_{\max }$ is the maximum stable bubble radius, and $u$ is the velocity difference across the tube. Another study [144] implemented a backlit digital imaging technique to obtain images of bubbles within the liquid film of adiabatic air-water horizontal annular flow. The aforementioned study pointed out that the bubbles were broken up under shear between the fast moving wave and the wall. The critical Weber number was proposed as [144]:

$W e_{c}=\frac{\rho_{l} u_{w}^{2} d_{\max }}{\sigma}$

where, $u_{w}$ is the mean disturbance wave velocity, and $d_{\max }$ is the maximum bubble diameter. However, the Weber number is also expressed as [4]:

$W e=\frac{\tau}{\sigma / d_{\max }}$

where, $\tau$ is a characteristic pressure or shear stress acting on the bubble, $\sigma$ is the interfacial tension and $\mathrm{d}_{\max }$ is the maximum bubble size, exceeding a critical value, $W e_{\text {crit }}$ a bubble of diameter larger than $d_{\max }$ breaks up due to the effects of turbulent velocity fluctuations. Following the Kolmogoroff-Hinze theory, assuming that $\tau_{c}$ scales as [4] :

$\tau_{c}=\frac{1}{2} \rho_{l} u_{c}^{2}$

where the characteristic velocity $u_{c}$ is defined as:

$u_{c}=\sqrt{2}\left(\varepsilon d_{\max }^{0}\right)^{1 / 3}$

where, $d_{\max }^{o}$ is the maximum bubble diameter that can exist when a single bubble flows in a full liquid pipe, and $\varepsilon$ is the energy dissipation due to turbulence and is expressed as [4]:

$\varepsilon=\frac{2 f u_{s l}^{3}}{D}$

where, $u_{l s}$ is the superficial velocity of the liquid phase. However, this study [4] considered the superficial velocity of the liquid phase as the mixture velocity, $u_{m}$. According to this hypothesis, $d_{\max }^{o}$ can be estimated as [4]:

$$
d_{\max }^{0}=W e_{c r i t}^{3 / 5}\left(\frac{\sigma}{\rho_{l}}\right)^{3 / 5} \varepsilon^{-2 / 5}
$$

\subsection{Minimum Bubble Diameter}

In literature several analytical formulations have also been proposed to estimate the minimum bubble size in twophase, two-component flow. As the two colliding bubbles approach each other, a liquid film is trapped between them. For coalescence to occur this liquid film must drain out and rupture. However, before coalescence occurs, the bubbles may separate if they possess sufficiently high energy [137]. The minimum bubble diameter with tangentially immobile interface can be expressed as follows [145]:

$d_{\min }=2.4\left(\frac{\sigma^{2} h^{2}}{\mu_{c} \rho_{c} \varepsilon}\right)^{1 / 4}$

where, $h$ is the film thickness at rupture between the two bubbles. The minimum diameter of a drop, which is stable against coalescence in a turbulent dispersion with tangentially immobile interface, is expressed as [138]:

$d_{\min }=\left(\frac{\sigma^{1.38} C_{L-V}^{0.46}}{0.0272 \mu_{c} \rho_{c}^{0.84} \varepsilon^{0.89}}\right)^{1 / 3.11}$

where, $C_{L-V}$ is the London-van der Waala constant and is assumed to be $10^{-28} \mathrm{Jm}$. Any bubble in a turbulent dispersion must be larger than $d_{\min }$ and smaller than $d_{\max }$ to prevent coalescence and breaking. Coalescence may be prevented by increasing turbulence intensity [138]. If $\mathrm{d}_{\min }=\mathrm{d}_{\max }$, the critical energy dissipation can be expressed as [138]:

$\varepsilon_{0}=A_{4} \frac{\sigma^{1.45} \mu_{c}^{2.91}}{\rho_{c}^{3} C_{L-V}^{1.36}}$

where, $A_{4}=\left(A_{1} / 3.19\right)^{1 / 0.11}$ and $A_{1}=0.725$ [142]. However, for air-water systems without any surfactants or impurities, the bubble surfaces are mobile and no explicit solution is available for $d_{\min }$ [137]. Implementing the numerical method [138], the following expression for the mobile bubble surface [138] can be written as:

$1363.3 \frac{\sigma^{1.29} \mu_{c}^{0.02} C_{L-V}^{0.26}}{E^{1.7} \mu_{d}^{1.02} \rho_{c}^{0.55} \varepsilon^{0.7} d_{\mathrm{min}}^{2.03}}$

$+217.3 \frac{\sigma^{1.38} C_{L-V}^{0.46}}{E^{0.7} \mu_{c}^{0.84} \rho_{c}^{0.84} \varepsilon^{0.89} d_{\mathrm{min}}^{3.11}}=1$

where, $\sigma$ is the surface tension of water, $\varepsilon$ is the turbulent kinetic energy dissipation rate per unit mass and $\rho$ and $\mu$ are the density and dynamic viscosity, respectively. Subscripts, $c$ and $d$ correspond to the continuous (i.e., water) and the dispersed phases (i.e., air), respectively. $C_{L-V}$ is the London-van-der Waals constant and $E$ is the dimensionless curvature radius of the liquid film between two colliding bubbles and is given by:

$E=12.61+2.166 \tan ^{-1}\left(2 M^{0.8}\right)$

$M$ is the interface mobility coefficient and is expressed as follows:

$M=1.12 \frac{\mu_{c}}{\mu_{d}}\left(\frac{\pi \sigma}{\rho_{c} \varepsilon^{2 / 3} d_{\mathrm{min}}^{5 / 3}}\right)^{1 / 2}$

A study [138] tested their numerical solution with experimental data and obtained a good consistency for the immobile bubble surface case. However, they did not verify their solution for the mobile surface case. 


\section{CONCLUSIONS}

In this paper, several advanced two-phase, gas-liquid measurement techniques with greater emphasis in the horizontal flow cases were examined. We focused on twophase pressure, void fraction and bubble size distribution measurement techniques. Due to the highly non-symmetric nature of two-phase gas-liquid horizontal flow systems, it has always been a challenge to obtain accurate data in this type of flow. In addition, the success of pressure and void fraction measurements in gas/liquid horizontal flow largely depends on the respective flow regime; whether it is dispersed, slug, or stratified flow. Measurement accuracy and characteristics depend on the phase velocity and air-toliquid ratio. In literature, most of the studies were conduced on vertical bubble columns rather than in a horizontal alignment. Based on pressure and photonics measurements in two-phase gas/liquid flow, several empirical equations have been developed. In our present study of air-water twophase horizontal flow $(6.35 \mathrm{~mm}$ ID diameter, $36.8 \mathrm{~cm}$ long pipe, air-to-liquid ratio $1-10 \%$, operating pressure in the ranges of $300 \mathrm{kPa}$ to $1.4 \mathrm{MPa}$ ) we would implement those empirical equations to explore the validity of those equations.

High performance dynamic and static pressure transducers would be reliable instruments in two-phase gas/liquid pressure measurements. Most of the void fraction measurements were intrusive in nature. Other methods have safety issues and accuracy challenges. However, the mechanical quick-closing-valve technique has been proven to be a more reliable and easy-to-implement method if the synchronization of the two closing valves can be assured. Also the online electrical process tomography method would be a valuable measurement tool in future to evaluate void fractions in multiphase flows. High-speed video and photonics measurements are also very reliable non-intrusive volume fraction and flow pattern estimation techniques, especially if one wants to measure unclosed multiphase flow behaviour (e.g. in spray). Generally, there are three kinds of methods used to identify two-phase flow regimes. The first one is the direct method. This method includes the direct identification of the flow regimes as to flow forms, such as the high-speed photography method. The second is the indirect method. This method includes the statistical analysis of measured signals, which reflect the fluctuant characteristic of two-phase flows, and the flow regimes. The third is the intrusive method. This method includes the placement of high performance sensing probes inserted inside the conduit, which provide a time varying signal. This method disturbs the local flow field significantly and in some cases could provide erroneous information. To the author's knowledge, different types of photonics measurements (high-speed photography, shadowgraphy, stroboscopic back illumination, high power pulsed laser) would be able to accurately provide the flow structure of two-phase gas/liquid flow. Information obtained from these photonics measurements could be coordinated with the flow transition maps and correlations provided by several researchers. However, most of the flow maps and correlations are designed for rectangular, vertical, and large diameter tubes. We should identify the applicability of this photonics measurement in our horizontal nozzle assembly (feeding conduit of $36.8 \mathrm{~cm}$ in length and $6.35 \mathrm{~mm}$ in $I D$ ). This would also assist us to accurately identify the flow transition region in a patented unique design of industrial nozzle assembly.

\section{ACKNOWLEDGEMENT}

Authors wish to acknowledge the financial support used to carry out for this study provided by Syncrude Canada Ltd, CRD grant, Alberta Ingenuity, and NSERC.

\section{NOMENCLATURE}

$A_{\text {pipe }}=$ Cross sectional area of feeding conduit or pipe $\left(\mathrm{m}^{2}\right)$

$A_{G} \quad=$ Area of the gas phase $\left(\mathrm{m}^{2}\right)$

$C_{D} \quad=$ Drag coefficient

$C=$ Air acceleration number (-)

$c_{1} \quad=$ Speed of sound $(\mathrm{m} / \mathrm{s})$

$d_{p} \quad=$ Particle diameter $(\mathrm{m})$

$d_{b} \quad=$ Bubble diameter $(\mathrm{m})$

$d_{1} \quad=$ Major axis length of the ellipsoid $(\mathrm{m})$

$d_{2} \quad=$ Minor axis length of the ellipsoid (m)

$\mathrm{d}_{\max } \quad=$ Maximum diameter of the bubble $(\mathrm{m})$

$d_{\max }^{o} \quad=$ Maximum bubble diameter that can exist when a single bubble flows in a full liquid pipe (m)

$\mathrm{d}_{\min } \quad=$ Minimum bubble diameter $(\mathrm{m})$

$D \quad=$ Diameter of the pipe $(\mathrm{m})$

$E \quad=$ Dimensionless curvature radius of the liquid film (-)

$f \quad=$ Arbitrary function

$\langle f\rangle_{t} \quad=$ Average time

$\langle f\rangle_{V} \quad=$ Average volume

$\langle f\rangle_{N} \quad=$ Ensemble average

$f_{m} \quad=$ Mixture friction factors (-)

$G \quad=$ Mixture velocity $(\mathrm{m} / \mathrm{s})$

g $\quad=$ Gravity $\left(\mathrm{m} / \mathrm{s}^{2}\right)$

$G_{s} \quad=$ Mass flux of gas phase $\left(\mathrm{kg} / \mathrm{m}^{2} . \mathrm{s}\right)$

$G_{l} \quad=$ Mass flux of liquid phase $\left(\mathrm{kg} / \mathrm{m}^{2} . \mathrm{s}\right)$

$h \quad=$ Film thickness at rupture between the two bubbles (m)

$k \quad=$ Polytropic constant

$K_{f} \quad=$ Friction coefficient (-)

$L \quad=$ Characteristic system length (m) 
$L=$ Characteristic slug wavelength (m)

$L_{i} \quad=$ Length of each liquid lump (m)

$l_{H} \quad=$ Bubble length parallel to the flow (m)

$l_{V} \quad=$ Bubble length perpendicular to the flow $(\mathrm{m})$

$l_{c} \quad=$ Closing length between the two valves $(\mathrm{m})$

$\dot{m}_{d} \quad=$ Mass flow rate of the dispersed phase $(\mathrm{kg} / \mathrm{s})$

$\dot{m}_{c} \quad=$ Mass flow rate of the continuous phase $(\mathrm{kg} / \mathrm{s})$

$m \quad=$ Total mass flow rate $(\mathrm{kg} / \mathrm{s})$

$M_{i} \quad=$ Mass of a liquid lump (or wave) of number $i$ ( $\mathrm{kg})$

$M \quad=$ Interface mobility coefficient (-)

$n_{p} \quad=$ Number of the particles on the image (-)

$N_{p} \quad=$ Volumetric particle concentration (-)

$o \quad=$ Overlapping parameter $(-)$

$P \quad=$ Pressure inside the pipe $(\mathrm{Pa})$

$P_{p} \quad=$ Pressure in the dispersed phase $(\mathrm{pa})$

$P_{c} \quad=$ Pressure in the continuous phase(pa)

$p_{v} \quad=$ Saturated vapor pressure of a bubble (pa)

$p_{\propto} \quad=$ Pressure far from bubble(pa)

$p_{b} \quad=$ Bubble pressure $(\mathrm{pa})$

$p_{g 0} \quad=$ Bubble partial pressure at a reference radius $(\mathrm{pa})$

$P^{*} \quad=$ Pressure at the cross-section where Mach number is one (pa)

$Q_{d} \quad=$ Volume flow rate of the dispersed phases $\left(\mathrm{m}^{3} / \mathrm{sec}\right)$

$Q_{c} \quad=$ Volume flow rate of the continuous phases $\left(\mathrm{m}^{3} / \mathrm{sec}\right)$

$R=$ Universal gas constant $\left(8.3144 \times 10^{-3}\right.$ $\mathrm{kJ} / \mathrm{mol} . \mathrm{K}$ )

$r \quad=$ Bubble radius $(\mathrm{m})$

$r_{0} \quad=$ Reference bubble size $(\mathrm{m})$

$r_{a} \quad=$ Radii for the major axes (m)

$r_{b} \quad=$ Radii for the minor axes $(\mathrm{m})$

$\left(r_{b}\right)_{\max }=$ Maximum stable bubble radius $(\mathrm{m})$

$r \quad=$ Radial distance from the axis of symmetry $(\mathrm{m})$

$R \quad=$ Pipe radius $(\mathrm{m})$

$S_{i} \quad=$ Area of the liquid lump $\left(\mathrm{m}^{2}\right)$
$T_{\text {sys }} \quad=$ System time scale $(\mathrm{s})$

$T=$ Absolute temperature $(293 \mathrm{~K})$

$T_{p} \quad=$ Temperature of the dispersed phase $(\mathrm{K})$

$T_{c} \quad=$ Temperature of the continuous phase $(\mathrm{K})$

$T_{\propto} \quad=$ Temperature far from the bubble $\mathrm{K}$

$t \quad=$ Time $(\mathrm{s})$

$t_{a c}=$ Asynchronization closing time (s)

$u_{c} \quad=$ Velocity of the continuous phase $(\mathrm{m} / \mathrm{s})$

$u_{p} \quad=$ Velocity of the dispersed phase $(\mathrm{m} / \mathrm{s})$

$u_{d} \quad=$ Velocity of the dispersed phase $(\mathrm{m} / \mathrm{s})$

$u_{m} \quad=$ Total or mixture velocity $\left(=u_{d s}+u_{c s}\right)(\mathrm{m} / \mathrm{s})$

$u_{d s} \quad=$ Superficial velocity of the dispersed phase $(\mathrm{m} / \mathrm{s})$

$u_{c s} \quad=$ Superficial velocity of the continuous phase $(\mathrm{m} / \mathrm{s})$

$u_{\propto} \quad=$ Fluid velocity far from the bubble $(\mathrm{m} / \mathrm{s})$

$u_{\infty} \quad=$ Terminal $/ \mathrm{rising} / \mathrm{settling}$ velocity $(\mathrm{m} / \mathrm{s})$

$u_{1} \quad=$ Shock speed $(\mathrm{m} / \mathrm{s})$

$u_{s g}^{*} \quad=$ Drift coefficients (-)

$u_{s l}^{*} \quad=$ Drift coefficients $(-)$

$u \quad=$ Velocity difference $(\mathrm{m} / \mathrm{s})$

$u_{w} \quad=$ Mean disturbance wave velocity $(\mathrm{m} / \mathrm{s})$

$V_{d} \quad=$ Volume of the dispersed phase $\left(\mathrm{m}^{3}\right)$

$V \quad=$ Total volume $/$ characteristics volume $\left(\mathrm{m}^{3}\right)$

$V \quad=$ Control volume size $\left(\mathrm{m}^{3}\right)$

$v_{p} \quad=$ Particle velocity $(\mathrm{m} / \mathrm{s})$

$X \quad=$ Martinelli parameter (-)

$x=$ Axial direction $(\mathrm{m})$

$Z \quad=$ Distance from the control volume to the out-offocus-particle $(\mathrm{m})$

\section{Greek Letters}

$\alpha \quad=$ Void fraction [-]

$\alpha_{H} \quad=$ Homogeneous void fraction [-]

$\tau_{p} \quad=$ Particle momentum response time (s)

$\tau_{c} \quad=$ Characteristic flow system time (s)

$\tau_{m} \quad=$ Momentum response time (s)

$\tau_{f} \quad=$ Characteristic time of the flow field $(\mathrm{s})$ 


$\begin{array}{ll}\rho_{p} & =\text { Particle density }\left(\mathrm{kg} / \mathrm{m}^{3}\right) \\ \rho_{d} & =\text { Particle density }\left(\mathrm{kg} / \mathrm{m}^{3}\right) \\ \rho_{c} & =\text { Continuous phase density }\left(\mathrm{kg} / \mathrm{m}^{3}\right) \\ \bar{\rho}_{p} & =\text { Bulk particle density }\left(\mathrm{kg} / \mathrm{m}^{3}\right) \\ \bar{\rho}_{d} & =\text { Bulk particle density }\left(\mathrm{kg} / \mathrm{m}^{3}\right)\end{array}$

$\bar{\rho}_{c} \quad=$ Bulk continuous phase density $\left(\mathrm{kg} / \mathrm{m}^{3}\right)$

$\rho_{m} \quad=$ Mixture density

$\mu_{c} \quad=$ Viscosity of the continuous phase $(\mathrm{kg} / \mathrm{m} . \mathrm{s})$

$\mu_{d} \quad=$ Viscosity of the dispersed phase $(\mathrm{kg} / \mathrm{m} . \mathrm{s})$

$\mu_{m} \quad=$ Mixture viscosity $(\mathrm{kg} / \mathrm{m} . \mathrm{s})$

$\lambda_{c o l}=$ Average distance between potentially colliding particles (m)

$\lambda_{r}=$ Average distance traveled by a particle during relaxation time $(\mathrm{m})$

$v \quad=$ Kinematic viscosity $\left(\mathrm{m}^{2} / \mathrm{s}\right)$

$v_{c}=$ Kinematic viscosity of the continuous phase $\left(\mathrm{m}^{2} / \mathrm{s}\right)$

$v_{d} \quad=$ Kinematic viscosity of the dispersed phase $\left(\mathrm{m}^{2} / \mathrm{s}\right)$

$\sigma \quad=$ Surface tension $(\mathrm{N} / \mathrm{m})$

$\varphi \quad=$ Velocity ratio

$\delta \quad=$ Thickness of the wall jet (m)

$\Delta t_{i} \quad=$ Residence time (s)

$\varepsilon=$ Energy dissipation $\left(\mathrm{m}^{2} / \mathrm{s}^{3}\right)$

$\lambda=$ Flow rate fraction (-)

$\lambda=$ Input liquid content (-)

$\alpha \quad=$ Void fraction (-)

$\chi \quad=$ Martinelli parameter (-)

$\mu \quad=$ Mean of the log-normal $P D F$ in the logarithmic variable

$\sigma=$ Standard deviation of the log-normal PDF in the logarithmic variable

$\theta \quad=$ Angle of inclination

\section{Subscripts}

c $\quad=$ Continuous phase

p or $\mathrm{d}=$ Particle or dispersed phase

$\mathrm{h}=$ Homogeneous

$\mathrm{s} \quad=$ Superficial

$$
\begin{array}{ll}
1 & =\text { Liquid } \\
\mathrm{g} & =\text { Gas } \\
\text { ave } & =\text { Average } \\
\text { crit } & =\text { Critical } \\
\max & =\text { Maximum } \\
\min & =\text { Minimum }
\end{array}
$$

\section{ABBREVIATIONS}
ALR $=$ Air to liquid ratio
$L D A=$ Laser-doppler-anemometry
$D D P I V=$ Defocusing digital particle image velocimetry
$D I P H=$ Digital image plane holography

\section{Dimensionless Groups}

$$
\begin{array}{ll}
N_{F r} & =\text { Froude number } \\
F r & =\text { Froude number } \\
F & =\text { Modified Froude number } \\
K n_{c} & =\text { Collision Knudsen number } \\
K n_{r} & =\text { Relaxation Knudsen number } \\
S t & =\text { Stokes number } \\
N_{b} & =\text { Body force number } \\
G a & =\text { Galileo number } \\
S t & =\text { Strouhal number } \\
\operatorname{Re}_{\mathrm{Re}_{\infty}} & =\text { Reynolds number } \\
\operatorname{Re}_{p} & =\text { Particle Reynolds number } \\
W e & =\text { Weber Number } \\
W e_{c} & =\text { Critical Weber number } \\
E o & =\text { Eotvos number } \\
M & =\text { Morton Number }
\end{array}
$$

\section{REFERENCES}

[1] Crowe, C.T. Multiphase flow handbook CRC: Taylor \& Francis, Boca Raton, FL 2006.

[2] Kabiri-Samani, A.R.; Borghei, S.M.; Saidi, M.H. Fluctuation of air-water two-phase flow in horizontal and inclined water pipelines. J. Fluids Eng.-Transact. Asme, 2007, 129(1), 1-14.

[3] Kleinstreuer, C. Two-phase flow: theory and applications. Taylor \& Francis, New York, NY, 2003.

[4] Andreussi, P.; Paglianti, A.; Silva, F.S. Dispersed bubble flow in horizontal pipes. Chem. Eng. Sci., 1999, 54(8), 1101-1107.

[5] Chen, X.T.; Cai, X.D.; Brill, J.P. A general model for transition to dispersed bubble flow. Chem. Eng. Sci., 1997, 52(23), 4373-4380.

[6] Gomez, L.E.; Shoham, O.; Schmidt, Z.; Chokshi, R.N.; Brown, A Northug, T. Unified Mechanicstic Model for Steady-State TwoPhase Flow in Wellbores and Pipelines, In proceedings-SPE Ann Technic. Conf., 1999. pp. 307-320.

[7] Daniels, L. Dealing with two-phase flows. Chem. Eng., 1995 102(6), 70-78.

[8] Delhaye, J.M. Two-phase flow patterns: Thermohydraulics of TwoPhase Systems for Industrial Design and Nuclear Engineering. McGraw-Hill New York, NY, 1981. 
[9] Ishii, M.; Hibiki, T. Thermo-fluid Dynamics of Two-Phase Flow Springer, US, 2005.

[10] Ni, J.; Beckermann, C. A Volume-Averaged 2-Phase Model for Transport Phenomena During Solidification. Metallurgic. Trans. BProcess Metallurgy, 1991, 22(3), 349-361.

[11] Soo, S. Multiphase Fluid Dynamics. Science Press, Beijing, P.R.C. and Gower Technical, Brookfield, MA, 1990.

[12] Whitaker, S. The Method of Volume Averaging. Springer, US, 2006.

[13] Boure, J.A.; Delhaye, J.M. General equations and two-phase flow modeling, handbook of multiphase system. McGraw-Hill, New York, NY, 1982

[14] Yadigaroglub, G.; Jr Lahey, R.T. On the various forms of the conservation equations in two-phase flow. Int. J. Multiphase Flow, 1976, 2(5-6), 477-94.

[15] Banerjee, S.; Chan, A.M.C. Separated flow models. 1. Analysis of the averaged and local instantaneous formulations. Int. J. Multiphase Flow, 1980, 6(1-2), 1-24.

[16] Drew, D.A. Two-fluid modeling. Renseelaer Polytecnic Institute Lecture Series, 1991.

[17] Lahey, R.T.J.; Drew, D.A. The three-dimensional time and volume averaged conservation equations of two-phase flow. Advances in Nuclear Science and Technology 20. Plenum Press, New York, NY, 1988

[18] Ransom, V.H.; Ramshaw, J.D. Discrete modeling considerations in multiphase fluid dynamics CRC press, Coca Raton, FL, 3-25, 1992.

[19] Taylor, G.I. The viscosity of a fluid containing small drops of another fluid. Proc. Royal Soc. Lond. Series, 1932, 138(834), 4148 .

[20] Wallis, G.B. One-Dimensional Two-Phase Flow. McGraw-Hill, New York, NY, 1969.

[21] Brady, J.F. The Einstein Viscosity Correction in N-Dimensions. Int. J. Multiphase Flow, 1984, 10(1), 113-114.

[22] Dukler, A.E.; Wicks, M.; Cleveland, R.G. Frictional pressure drop in two-phase flow: an approach through similarity analysis. AIChE $J, \mathbf{1 9 6 4}, 10,44-51$

[23] McAdams, W.; Wood, W.; Bryan, R. Vaporization inside horizontal tubes-II-benzene-oil mixtures. Trans. ASME, 1942, 64, 193

[24] Cicchitt, A.L.C.; Silvestri, M. Two-phase cooling experiments pressure drop, heat transfer and burnout measurement. Energia Nuclear, 1960, 7(6), 407-425.

[25] Zuber, N.; Findlay, J.A. Average volumetric concentration in twophase flow systems. J. Heat Transfer, 1965, 87, 453-468.

[26] Kroeger, P.G.; Zuber, N. An analysis of effects of various parameters on average void fractions in subcooled boiling. Int. $J$. Heat Mass Transfer, 1968, 11(2), 211-217.

[27] Ishii, M. Drift flux model and derivation of kinematic constitutive laws: two-phase flow and heat transfer. S. Kakac and F. Mayinger (Eds.), 1. Hemisphere Publication Corporation, Washington DC, 1976.

[28] Li, A.; Ahmadi, G. Computer-simulation of particle deposition in the upper tracheobronchial tree. Aerosol. Sci. Technol., 1995, 23(2), 201-223.

[29] Kim, C.; Iglesias, A. Deposition of inhaled particles in bifurcating airway models: I. Inspiratory deposition. J. Aerosol. Med., 1989, 2, $1-14$.

[30] Li, A.; Ahmadi, G. Dispersion and deposition of spherical-particles from point sources in a turbulent channel flow. Aerosol. Sci. Technol., 1992, 16(4), 209-226.

[31] Patankar, N.A.; Joseph, D.D. Modeling and numerical simulation of particulate flows by the Eulerian-Lagrangian approach. Int. J. Multiphase Flow, 2001, 27(10), 1659-1684.

[32] Snider, D.M.; O'Rourke, P.J.; Andrews, M.J. Sediment flow in inclined vessels calculated using a multiphase particle-in-cell model for dense particle flows. Intl. J. Multiphase Flow, 1998, 24(8), 1359-1382.

[33] Brill, J.P.; Mukherjee, H. Multiphase Flow in Wells, Henry L. Doherty Series, Society of Petroleum Engineers, 17. Henry L. Doherty Series, Society of Petroleum Engineers, Richardson, TX, 1999.

[34] Baruna, S.; Shamara, Y.; Brosius, M.G. Two-phase flow model aids flare network design. Oil Gas J., 1990, 90(4), 90-94.

[35] Gudmundsson, J.S. Method for determination of flow rate especially two-phase flow. Norwegian Patent, No. 944264. 1994
[36] Erickson, D.; Twaite, D. Pipeline integrity monitoring system for leak detection, control, and optimization of wet gas pipelines, 1996 SPE annual technical conference and exhibition, Denver CO, 1196, pp. 335-347.

[37] Lahey, R.T. Void wave propagation phenomena in two-phase flow. AIChE J., 1991, 37(1), 123-73

[38] Garcia, F.; Garcia, R.; Padrino, J.C.; Mata, C.; Trallero, J.L.; Joseph, D.D. Power law and composite power law friction factor correlations for laminar and turbulent gas-liquid flow in horizontal pipelines. Int. J. Multiphase Flow, 2003, 29(10), 1605-624.

[39] Beggs, H.; Brill, J. A study of two phase flow in inclined pipes. $J$. Pet. Technol., 1973, 25, 607-617.

[40] Beattie, D.; Whalley, P. A simple two-phase frictional pressure drop calculation method. Int. J. Multiphase Flow, 1982, 83-87.

[41] Patankar, N.A.; Joseph, D.D.; Wang, J.; Barree, R.D.; Conway, M.; Asadi, M. Power law correlations for sediment transport in pressure driven channel flows. Int. J. Multiphase Flow, 2002, 28(8), 12691292.

[42] Crowe, C.T. Multiphase flow handbook CRC: Taylor \& Francis, Boca Raton, FL 2006.

[43] Mata, C.; Vielma, J.; Joseph, D. Power law correlations for gas/liquid flow in a flexible pipeline simulating terrain variation. Int. J. Multiphase Flow, submitted for publication, Also see $<$ http://www.aem.umn.edu/people/faculty/joseph/PLcorrelations/docs-ln/PLC-FlexPipe.pdf $>$, [Accessed in 2002].

[44] Martinelli, R.C.; Nelson, D.B. Prediction of pressure drop during forced-circulation boiling of water. Trans. ASME, 1948, 70, 695702.

[45] Zielinski, P.B.; Willemonte, J.R. Effect of viscosity on vortexorifice flow. J. Hydr. Div., ASCE, 1968, 94(3), 195-205.

[46] Levy, S. Two-Phase Flow in Complex Systems. Wiley, New York, 1999.

[47] Shedd, T.A.; Newell, T.A. Characteristics of the liquid film and pressure drop in horizontal, annular, two-phase flow through round, square and triangular tubes. J. Fluids Eng.-Trans. ASME, 2004, 126(5), 807-817.

[48] Hurlburt, E.T.; Newell, T.A. Optical measurement of liquid film thickness and wave velocity in liquid film flows. Exp. Fluids, $\mathbf{1 9 9 6}$ 21(5), 357-362.

[49] Shedd, T.A.; Newell, T.A. Automated optical liquid film thickness measurement method. Rev. Sci. Instrum., 1998, 69(12), 4205-4213.

[50] Ribeiro, A.M.; Ferreira, V.; Campos, J.B.L.M. On the comparison of new pressure drop and hold-up data for horizontal air-water flow in a square cross-section channel against existing correlations and models. Int. J. Multiphase Flow, 2006, 32, 1029-1036.

[51] Sawai, T.; Kaji, M.; Kasugai, T.; Nakashima, H.; Mori, T. Gasliquid interfacial structure and pressure drop characteristics of churn flow. Exp. Thermal Fluid Sci., 2004, 28, 597-606.

[52] Vlachos, N.A. Studies of Wavy Stratified and Stratified/Atomization Gas-Liquid Flow. J. Energy Res. Technol. Trans. ASME, 2003 125, 131-136.

[53] Cole, J.S.; Donnelly, G.F.; Spedding, P.L. Friction factors in twophase horizontal pipe flow. Int. Commun. Heat Mass Transfer, 2004, 31(7), 909-917.

[54] Plaskowski, A.; Beck, M.S.; Thorn, R.; Dyakowski, T. Imaging Industrial Flows: Applications of Electrical Process Tomography Institute of Physics Pub., Bristol, UK, Philadelphia 1995.

[55] Beck, M.S.; Dyakowski, T.; Williams, R.A. Process Tomography the state of the art. ransact. Inst. Measure. Control, 1998, 20(4), 163-177.

[56] Reinecke, N.; Petritsch, G.; Schmitz, D.; Mewes, D. Tomographic measurement techniques - visualization of multiphase flows. Chem Eng. Technol., 1998, 21 (1), 7-18.

[57] Shao, F.; Mong, Q. A method for measuring low capacitance for tomography. Rev. Sci. Instrume., 1999, 70(7), 3177-3179.

[58] Jeanmeure, L.F.C.; Dyakowski, T.; Zimmerman, W.B.J.; Clark, W Direct flow-pattern identification using electrical capacitance tomography. Exp. Thermal Fluid Sci., 2002, 26 763-773.

[59] Cartellier, A. Optical probes for local void fraction measurements: Characterization of performance. Rev. Sci. Instrum., 1990, 61(2), 874-886.

[60] Cartellier, A.; Achard, J.L. Local phase detection probes in fluid/fluid two-phase flows. Rev. Sci. Instrum., 1991, 62(2), 279 303. 
[61] Serdula, C.D.; Loewen, M.R. Experiments investigating the use of fiber-optic probes for measuring bubble-size distributions. IEEE $J$. Oceanic Eng., 1998, 23(4), 385-339.

[62] Changa, K.; Lim, H.; Su, C.B. Fiber optic reflectometer for velocity and fraction ratio measurements in multiphase flows. Rev. Sci. Instrum., 2003, 74(7), 3559-3565.

[63] Pettigrew, M.J.; Zhang, C.; Mureithi, N.W.; Pamfil, D. Detailed flow and force measurements in a rotated triangular tube bundle subjected to two-phase cross-flow. J. Fluids Struct., 2005, 20(4), 567-575.

[64] Hamad, F.A.; Pierscionek, B.K.; Bruun, H.H. A dual optical probe for volume fraction, drop velocity and drop size measurements in liquid-liquid two-phase flow. Measure. Sci. Technol., 2000, 11(9), 1307-1318.

[65] Miller, N.; Mitchie, R.E. Measurement of local voidage in liquid/gas two-phase flow systems. J. Br. Nucl. Energy Soc., 1970, 9, 94-100.

[66] Spindler K, B.M., Lorenz G, Erhard A and Hahne E ; Measurements in vertical gas-liquid two-phase flows using an optical fiber probe, Proc. 1st World Conf. on Experimental Heat Transfer, Fluid Mechanics and Thermodynamics (Dubrovnik), 1988, pp. 348-57.

[67] Kennedy, T.D.A.; Collier, J.G. The structure of an impinging gas jet submerged in a liquid multi-phase flow systems. Inst. Chem. Eng. Symp. Ser. 38 II, 1974, paper J4.

[68] Calderbank, P.H.; Pereira The prediction of distillation plate efficiencies from froth properties J. Chem. Eng. Sci., 1977, 32, 1427-33.

[69] Bell, R.; Boyce, B.E.; Collier, J.G.T. The structure of a submerged impinging gas jet. J. Br. Nucl. Energy Soc., 1972 11, 183-93.

[70] Abro, E.; Khoryakov, V.A.; Johansen, G.A.; Kocbach, L. Determination of void fraction and flow regime using a neural network trained on simulated data based on gamma-ray densitometry. Measure. Sci. Technol., 1999, 10(7), 619-630.

[71] Jiang, Y.J.; Rezkallah, K.S. An experimental-study of the suitability of using a gamma densitometer for void fraction measurements in gas-liquid flow in a small diameter tube. Measurement Sci. Technol., 1993, 4(4), 496-505.

[72] Rodriguez, O.M.H.; Oliemans, R.V.A. Experimental study on oilwater flow in horizontal and slightly inclined pipes. Int. J. Multiphase Flow, 2006, 32(3), 323-343.

[73] Heidrick, T.R.; Saltvold, J.R. Cross-section average density and mass flux measurements in two-phase flow through pipes, measurement in polyphase flow. The American society of mechanical engineers, San Francisco, CA, December 10-15, 1978,

$$
1-9 \text {. }
$$

[74] Ahmed, W.H. Capacitance sensorsor void-fraction measurements and flow-pattern identification in air-oil two-phase flow. IEEE Sensors J., 2006, 6(5), 1153-1163.

[75] Pawloski, J.L.; Ching, C.Y.; Shoukri, M. Measurement of void fraction and pressure drop of air-oil two-phase flow in horizontal pipes. J. Eng. Gas Turbines Power-Trans. ASME, 2004, 126(1), 107-118.

[76] Elkow, K.J.; Rezkallah, K.S. Void fraction measurements in gasliquid flows using capacitance sensors. Measurement Sci. Technol., 1996, 7(8), 1153-1163.

[77] Darnault, C.J.G.; Dicarlo, D.A.; Bauters, T.W.J.; Steenhuis, T.S.; Parlange, J.Y.; Montemagno, C.D.; Baveye, P. Visualization and measurement of multiphase flow in porous media using light transmission and synchrotron X-rays, Visualization and Imaging in transport phenomena. Ann. N. Y. Acad. Sci., 2002. pp. 103-110.

[78] Kehler, P.; Thome, J.R. Two-phase flow measurement by pulsed neutron activation techniques. Measurements in polyphase flows, The American society of mechanical engineers, San Francisco, CA, December 10-15, 1978.

[79] Snell, C.C.; Dechene, R.L.; Nweton, R.E. Two-phase relative volume fraction measurement with a rotating filed conductance gauge. Measurements in polyphase flows, The American society of mechanical engineers, San Francisco, CA, December 10-15, 1978.

[80] Chang, J.S.; Ichikawa, Y.; Irons, G.A. Flow regime characterization and liquid film thickness measurement in horizontal gas-liquid two-phase flow by an ultrasonic method. Measurements in polyphase flows, AIAA/ASME joint fluids, plasma, thermophysics and heat transfer conference, St. Louis, Missouri, June 7-11, 1982.
[81] Fossa, M.; Guglielmini, G. Pressure drop and void fraction profiles during horizontal flow through thin and thick orifices. Exp. Thermal Fluid Sci., 2002, 26, 513-523.

[82] Everson, J. Foster-Miller, Inc. See also:http://www.fostermiller.com/projectexamples/cc_icd_sensor_development/microwav e_flow_sensor.htm. 2005.

[83] Koyama, S.; Lee, J.; Yonemoto, R. An investigation on void fraction of vapor-liquid two-phase flow for smooth and microfin tubes with R134a at adiabatic condition. Int. J. Multiphase Flow, 2004, 30(3), 291-310.

[84] Kim, H.Y.; Koyama, S.; Matsumoto, W. Flow pattern and flow characteristics for counter-current two-phase flow in a vertical round tube with wire-coil inserts. Int. J. Multiphase Flow, 2001, 27(12), 2063-2081.

[85] Spedding, P.L.; Woods, G.S.; Raghunathan, R.S.; Watterson, J.K. Vertical two-phase flow - Part II: Experimental semi-annular flow and hold-up. Chem. Eng. Res. Design, 1998, 76(A5), 620-627.

[86] Lemonnier, H.; Nakach, R.; Favreau, C.; Selmerolsen, S. Sensitivity Analysis of an Impedance Void Meter to the Void Distribution in Annular-Flow - a Theoretical-Study. Nucl. Eng. Design, 1991, 126(1), 105-112.

[87] Bjork, E. A simple technique for refrigerant mass measurement. Appl. Thermal Eng., 2005, 25, 1115-1125.

[88] Chien, K.-H.; Lin, W.-K.; Tsai, Y.-C. Effect of the side-tube configuration on the void fraction measurement. Nucl. Technol., 1997, 120(2), 171-178.

[89] Flemmer, R.L.C.; Clark, N. A technique for synchronizing valves and determining bubble rise velocities in two-phase flow, Fluid engineering winter annual meeting, ASME, New Orleans, LA, December 9-14, pp1-5, 1984.

[90] Coleman, J.W.; Garimella, S. Characterization of two-phase fow patterns in small diameter round and rectangular tubes. Int. J. Heat Mass Transfer, 1999, 42(15), 2869-2881.

[91] Al-Wazzan, A.; Than, C.F.; Moghavvemi, M.; Yew, C.W. Video imaging measurement of interfacial wave velocity in air-water flow through a horizontal elbow. Photonic Systems and Applications, Yakov S. Sidorin, Dingyuan Tang, Editors, Proceedings of SPIE, 2001, 4595, 243-253.

[92] Augier, F.; Morchain, J.; Guiraud, P.; Masbernat, O. Volume fraction gradient-induced flow patterns in a two-liquid phase mixing layer. Chem. Eng. Sci., 2003, 58, 3985-3993.

[93] Cui, Z.; Fan, L.S. Turbulence energy distributions in bubbling gasliquid and gas-liquid-solid \&ow systems. Chem. Eng. Sci., 2004, 59 $1755-1766$.

[94] Der, D.B.; Sommerfeld, M. An advanced LIF-PLV system for analysing the hydrodynamics in a laboratory bubble column at higher void fractions. Exper. Fluids, 2002, 33, 826-837.

[95] Hardalupas, Y.; Horender, S. Fluctuations of particle concentration in a turbulent two-phase shear layer Int. J. Multiphase Flow, 2003, 29, 1645-1667.

[96] Hassan, Y.; Blanchat, T. Full-field bubbly flow velocity measurements by digital image pulsed laser velocimetry. Exp. Fluids, 1991, 11, 293-301.

[97] Kashdana, J.T.; Shrimptona, J.S.; Whybrew, A. A digital image analysis technique for quantitative characterisation of high-speed sprays. Optics Lasers Eng., 2007, 45, 106-115.

[98] Kawaguchi, T.; Akasaka, Y.; Maeda, M. Size measurements of droplets and bubbles by advanced interferometric laser imaging technique. Measure. Sci. Technol., 2002, 13, 308-316.

[99] Kowalewski, T.A. Particle image velocimetry and thermometry for two-phase flow problems. Ann. N.Y. Acad. Sci., 2002, 972, 213222.

[100] Murai, Y.; Oishi, Y.; Takeda, Y.; Yamamoto, F. Turbulent shear stress profiles in a bubbly channel flow assessed by particle tracking velocimetry. Exp. Fluids, 2006, 41, 343-352.

[101] Ottens, M.; Klinkspoor, K.; Hoefsloot, H.C.J.; Hamersma, P.J. Wave characteristics during cocurrent gas \pm liquid pipe flow. Exp. Thermal Fluid Sci., 1999, 19, 140-150.

[102] Shamoun, B.; Beshbeeshy, M.E.; Bonazza, R. Light extinction technique for void fraction measurements in bubbly flow. Exper. Fluids, 1999, 26 16-26.

[103] Sunde, C.; Avdic, S.; Pazsit, I. Classification of two-phase flow regimes via image analysis and a neuro-wavelet approach. Prog. Nucl. Energy, 2005, 46(3-4), 348-358. 
[104] Tafreshi, Z.M.; Kirpalani, D.; Bennett, A.; McCracken, T.W. Improving the efficiency of fluid cokers by altering two-phase feed characteristics. Powder Technol., 2002, 125, 234- 241.

[105] Tu, X.; Tragardh, C. Methodology development for the analysis of velocity particle image velocimetry images of turbulent, bubbly gas-liquid flows. Measure. Sci. Technol., 2002, 13, 1079-1086.

[106] Taitel, Y.; Dukler, A.E. A model for predicting flow regime transitions in horizontal and near horizontal gas-liquid flow. AIChE $J$, 1976, 22(2), 47-55

[107] Lambrechts, A. Heat transfer performance during in-tube condensation in horizontal smooth, micro-fin and herringbone tubes, University of Johannesburg, Mechanical and Manufacturing Engineering, 2005.

[108] Breber, G.; Palen, J.; Taborek, J. Prediction of horizontal tubeside condensation of pure components using flow regime criteria. $J$. Heat Transfer, 1980, 102, 471-476.

[109] Ewing, M.E.; Weinandy, J.J.; Christensen, R.N. Observation of two-phase flow patterns in a horizontal circular channel. Heat Transfer Eng., 1999, 20(1), 9-13.

[110] Baker, O. Simultaneous flow of oil and gas. Oil Gas J., 1954, 53, 185-195.

[111] Whalley, P.B. Boiling, Condensation and Gas-Liquid Flow. Oxford, New York, 1987.

[112] Mandhane, J.M.; Gregory, G.A.; Aziz, A. A flow pattern map for gas-liquid flow in horizontal pipes. Int. J. Multiphase Flow, 1974, 1, 537-553.

[113] Damianides, C.; Westwater, J.W., 1988. Two phase flow patterns in a compact heat exchanger and in small tubes, Proceedings of Second U.K. National Conference On Heat Transfer, vol II, Glasgow, Scotland, pp. 1257-1268.

[114] Hesketh, R.P.; Etchells, A.W.; Russell, T.W.F. Experimental observations of bubble breakage in turbulent flow. Ind. Eng. Chem. Res., 1991, 30(5), 835-841.

[115] Hesketh, R.P.; Etchells, A.W.; Russell, T.W.F. Bubble breakage in pipeline flow. Chem. Eng. Sci., 1991 46, 1-9.

[116] Hesketh, R.P.; Russell, T.W.F.; Etchells, A.W. Bubble size in horizontal pipelines. AIChE J., 1987, 33, 663-667.

[117] Walter, J.F.; Blanch, H.W. Bubble break-up in gas-liquid bioreactors: break-up in turbulent flows. Chem. Eng. J., 1986, 32, B7-B17.

[118] Simmons, M.J.H.; Azzopardi, B.J. Drop size distributions in dispersed liquid-liquid pipe flow. Int. J. Multiphase Flow, 2001, 27, 843-859.

[119] Angeli, P. Droplet size in two-phase liquid dispersed pipeline flows. Chem. Eng. Technol., 2001, 24, 431-434.

[120] Angeli, P.; Hewitt, G.F. Drop size distributions in horizontal oilwater dispersed flows. Chem. Eng. Sci., 2000, 55, 3133-3143.

[121] Kostoglou, M.; Karabelas, A.J. On the attainment of steady state in turbulent pipe flow of dilute dispersions. Chem. Eng. Sci., 1998, 53, 505-513.

[122] Parthasarathy, R.; Jameson, G.J.; Ahmed, N. Bubble breakup in stirred vessels-prediction of the Sauter mean diameter. Trans. IChemE, 1991, 69 (Part A), 295-301.

[123] Karabelas, A.J. Droplet size spectra generated in turbulent pipe flow of dilute liquid/liquid dispersions. AIChE J., 1978, 24, 170180 .

[124] Kubie, J.; Gardner, G.C. Drop sizes and drop dispersion in straight horizontal tubes and in helical coils. Chem. Eng. Sci., 1977, 32, 195-202.
[125] Holmes, T.L. Fluid mechanics of horizontal bubble flow, University of Delaware, 1973.

[126] Swartz, J.E.; Kessler, D.P. Single drop breakup in developing turbulent pipe flow. AIChE J., 1970, 16, 254-260.

[127] Collins, S.B.; Knudsen, J.G. Drop-size distributions produced by turbulent pipe flow of immiscible liquids. AIChE J., 1970, 16 , 1072-1080.

[128] Ward, J.P.; Knudsen, J.G. Turbulent flow of unstable liquid-liquid dispersions: drop sizes and velocity distributions. AIChE J., $\mathbf{1 9 6 7 ,}$ $13,356-365$

[129] Kolmogoroff, A.N. On the breaking of drops in turbulent flow Dokl. Akad. Nauk. SSSR 66, 825-828., 1949.

[130] Kashdan, J.T.; Shrimpton, J.S.; Whybrew, A. Two-phase flow characterization by automated digital image analysis. Part 1: fundamental principles and calibration ofthe technique. Part Syst. Charact., 2003 20, 387-397.

[131] Yule, A.J.; Chigier, N.A.; Cox, N.W. Measurement of Particle Sizes in Sprays by the Automated Analysis of Spark Photographs. Particle Size Analysis. Heyden Press, 61-73, 1978.

[132] Lecuona, A.; Sosa, P.A.; Rodriguez, P.A.; Zequeira, R.I Volumetric characterization of dispersed two-phase flows by digital image analysis. Measure. Sci. Technol., 2000 11, 11521161.

[133] Sotiriadis, A.A.; Thorpe, R.B.; Smith, J.M. Bubble size and mass transfer characteristics of sparged downwards two-phase flow. Chem. Eng. Sci., 2005, 60, 5917-5929.

[134] Leifer, I.; Leeuwb, G.D.; Kunzb, G.; Cohenb, L.H. Calibrating optical bubble size by the displaced-mass method. Chem. Eng. Sci., 2003, 58, 5211-5216.

[135] Sam, A.; Gomez, C.O.; Finch, J.A. Axial velocity profiles of single bubbles in water/froth. Int. J. Mineral Processi., 1996, 47, 177-196.

[136] Marco, P.D.; Grassi, W.; Memoli, G. Experimental study on rising velocity of nitrogen bubbles in FC-72. Int. J. Thermal Sci., 2003 , 42 435-446.

[137] Razzaque, M.M.; Afacan, A.; Liu, S.; Nandakumar, K.; Masliyah, J.H.; Sanders, R.S. Bubble size in coalescence dominant regime of turbulent air-water flow through horizontal pipes. Int. J. Multiphase Flow, 2003, 29, 1451-1471.

[138] Liu, S.; Li, D. Drop coalescence in turbulent dispersions. Chem Eng. Sci., 1999, 54, 5667-5675.

[139] Shinnar, R. On the behaviour of liquid dispersions in mixing vessels. J. Fluid Mech., 1961, 10, 259-275.

[140] Hibiki, T.; Goda, H.; Kim, S.; Ishii, M.; Uhle, J. Structure of vertical downward bubbly flow. Int. J. Heat Mass Transfer, 2004, 47, 1847-1862.

[141] Levich, V.G. Physiochemical Hydrodynamics. Prentice Hall, Englewood Cliffs, N.J., 1962, p. 464.

[142] Hinze, J.O. Fundamentals of the hydrodynamic mechanism of splitting in dispersion processes. AIChE J, 1955, 1, 289-295.

[143] Thorpe, R.B.; Evans, G.M.; Zhang, K.; Machniewski, P.M. Liquid recirculation and bubble breakup beneath ventilated gas cavities in downward pipe flow. Chem. Eng. Sci., 2001, 56, 6399-6409.

[144] Rodriguez, D.J.; Shedd, T.A. Entrainment of gas in the liquid film of horizontal, annular, two-phase flow. Int. J. Multiphase Flow, 2004, 30, 565-583.

[145] Thomas, R.M. Bubble coalescence in turbulent flows. Int. J Multiphase Flow, 1981, 7, 709-717. 